Louisiana State University

LSU Digital Commons

2002

\title{
One-week stability of forearm venous outflow as assessed by venous occlusion plethysmography
}

Jennifer Pitre Ortego

Louisiana State University and Agricultural and Mechanical College

Follow this and additional works at: https://digitalcommons.Isu.edu/gradschool_theses

Part of the Kinesiology Commons

\section{Recommended Citation}

Ortego, Jennifer Pitre, "One-week stability of forearm venous outflow as assessed by venous occlusion plethysmography" (2002). LSU Master's Theses. 3802.

https://digitalcommons.Isu.edu/gradschool_theses/3802

This Thesis is brought to you for free and open access by the Graduate School at LSU Digital Commons. It has been accepted for inclusion in LSU Master's Theses by an authorized graduate school editor of LSU Digital Commons. For more information, please contact gradetd@lsu.edu. 


\author{
A Thesis \\ Submitted to the Graduate Faculty of the \\ Louisiana State University and \\ Agricultural and Mechanical College \\ In partial fulfillment of the \\ Requirements for the degree of \\ Master of Science
}

in

The Department of Kinesiology

by

Jennifer P. Ortego

B.S., Louisiana State University, 1998

May 2002 


\section{Table of Contents}

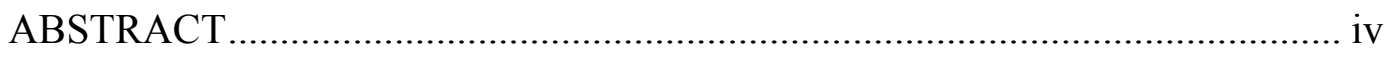

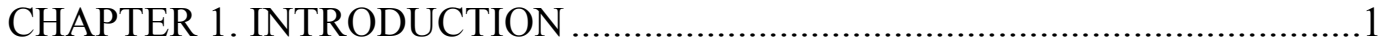

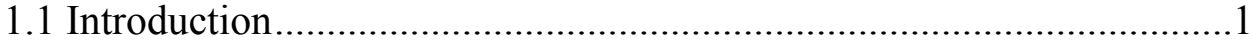

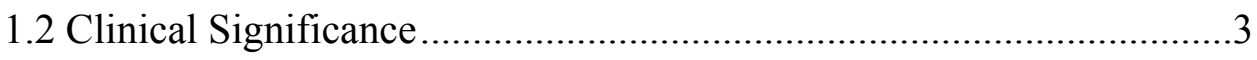

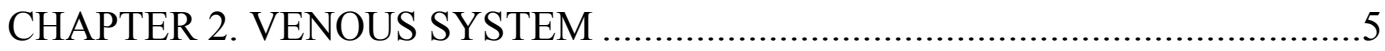

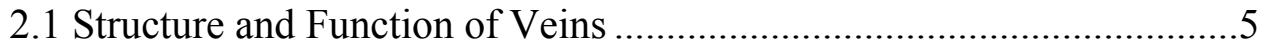

2.2 Biomechanical Control ...............................................................11

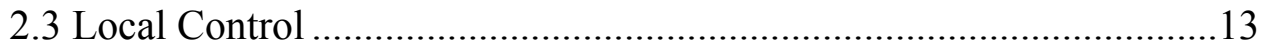

2.3.1 Metabolic Control .............................................................13

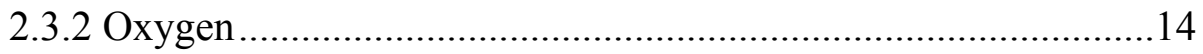

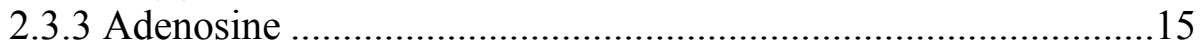

2.3.4 pH, $\mathrm{Pco}_{2}$, Lactate, Potassium and Osmolarity .........................15

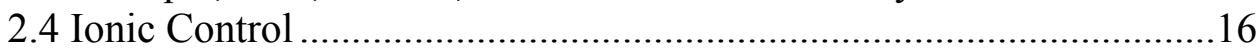

2.4.1 Sodium ......................................................................... 16

2.4.2 Potassium .........................................................................18

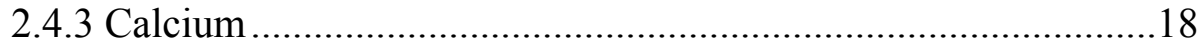

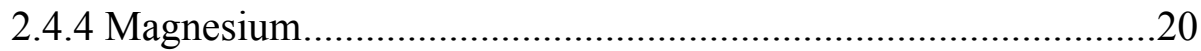

2.4.5 Chloride........................................................................21

2.5 Hormonal Control (Constrictor Agents) ........................................22

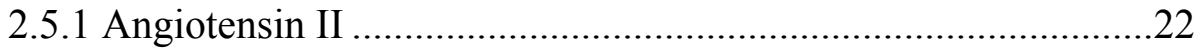

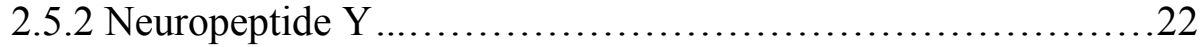

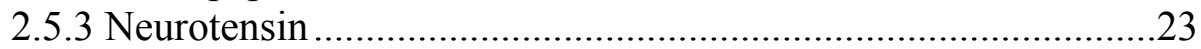

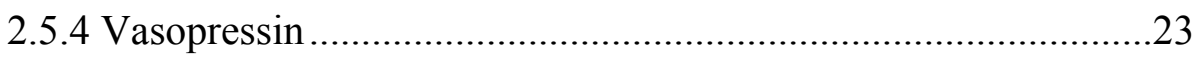

2.6 Relaxing Agents........................................................................24

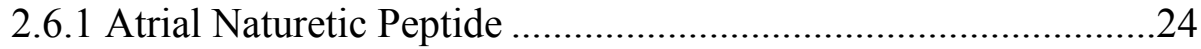

2.6.2 Calcitonin Gene-Related Peptide.............................................24

2.6.3 Vasoactive Intestinal Peptide.................................................25

2.7 Agents with Constrictor and Relaxant Effects ..................................25

2.7.1 Bradykinin.......................................................................25

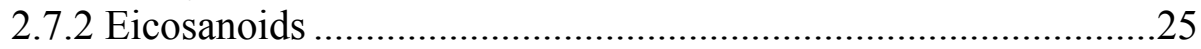

2.7.3 Endothelial Relaxing Factor .............................................27

2.8 Endothelial Constrictor Factors ....................................................28

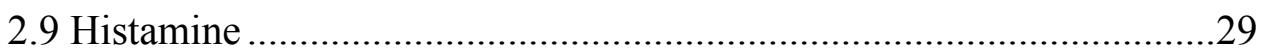

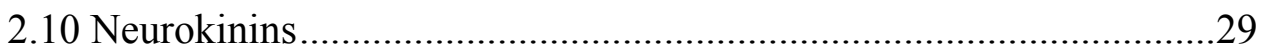

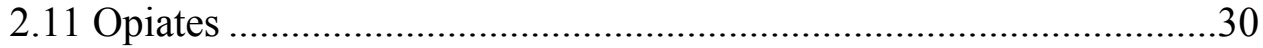

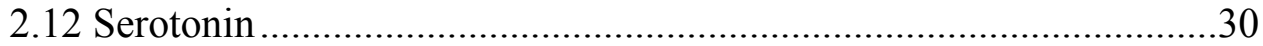

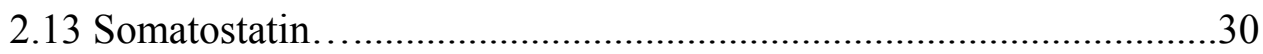

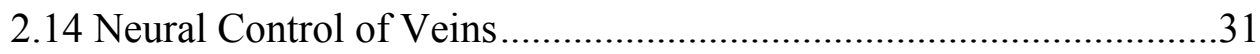

2.15 Influence of Temperature on Venous Tone .....................................31

2.16 Effects of Age on Venous Tone................................................... 31

2.17 Effects of Disease on Venous Function ............................................32 


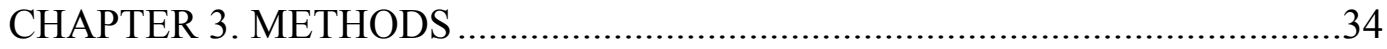

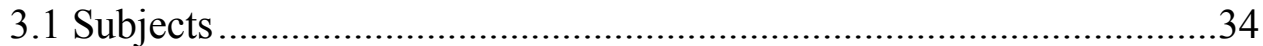

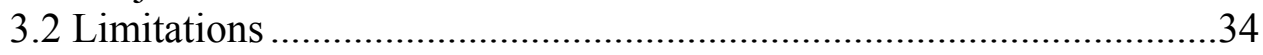

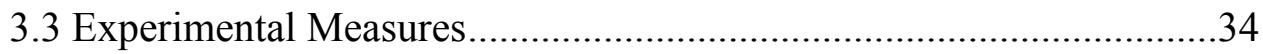

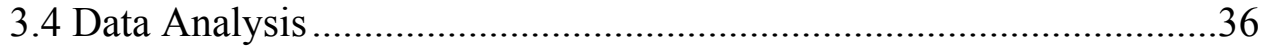

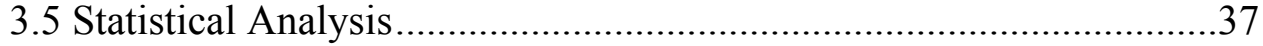

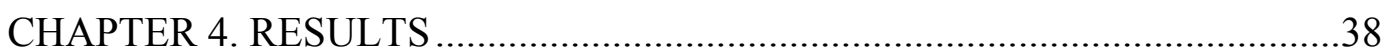

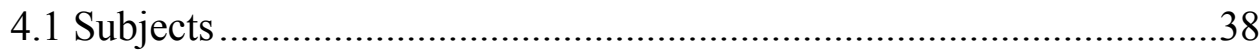

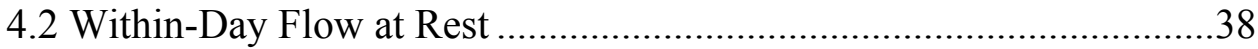

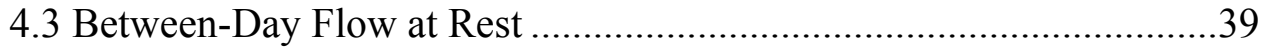

4.4 Between-Day Flow Following Occlusion.........................................40

4.5 Correlation Among Variables .......................................................40

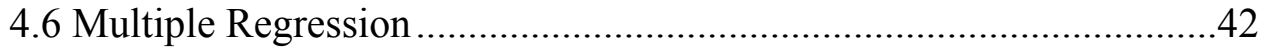

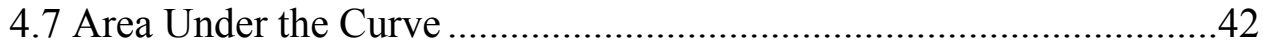

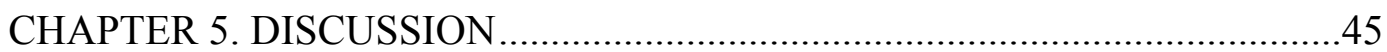

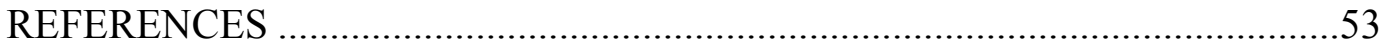

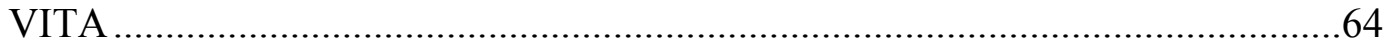




\begin{abstract}
The aim of this study was to test short-term and long-term reliability of venous outflow (VO) indices using the venous occlusion plethysmography technique. A secondary purpose was to compare venous measures to age, gender and various anthropometrical measures. The study group consisted of apparently healthy males and females, aged 18 to 80 years. Venous indices were under measures on two occasions (1 week apart), under the conditions of rest and following 5 min of upper arm occlusion. Venous outflow measures were calculated from the area under the curve (AUC) as well as the plethysmographic curve technique at the time $.5\left(\mathrm{VO}_{.5}\right), 2\left(\mathrm{VO}_{2}\right)$ and the time interval between .5-2 seconds $\left(\mathrm{VO}_{.5-2}\right)$. Venous capacitance (VC) was calculated by measuring the distance in $\mathrm{mm}$ from the baseline to the maximum height of the inflow curve and dividing this distance by the height of the calibration mark. Intraclass correlation coefficient (ICC) revealed higher within-day reliability than one-week reliability for markers: ICC's $=.931$ vs. $.622, .948$ vs. $.709, .965$ vs. .518 , and .971 vs. .431 for $\mathrm{VC}, \mathrm{VO}_{.5}, \mathrm{VO}_{2}$ and $\mathrm{VO}_{.5-2}$, respectively. One-week reliability for these measures following occlusion were: ICC's $=.562, .701, .646$ and .639 for all indices. Pearson correlation revealed associations between $\mathrm{VO}_{.5}$ and $\mathrm{VO}_{2}$ with arm length $(\mathrm{R}=-.344, \mathrm{p}<$ $.09 ; \mathrm{R}=-.430, \mathrm{p}<.03)$, respectively. Age was associated with $\mathrm{VO}_{.5-2}(\mathrm{R}=-.340, \mathrm{p}<.10)$. In addition, there were gender differences in VC $(p<.009)$. Finally, a stepwise regression analysis was performed showing significant predictive value of venous measures, in relation to body size, with arm length $(F=4.979, \mathrm{p}<.03)$ and gender $(\mathrm{F}=7.862, \mathrm{p}<.01)$. Short-term VO measures showed stronger reliability than long-term measures.
\end{abstract}


Additionally, it appears that vessel length and gender have an important influence on venous outflow. 


\section{Chapter 1}

\section{Introduction}

\subsection{Introduction}

The venous system is a vast network of vessels that play a critical role in homeostasis. One of the primary roles of the venous system is that of capacitance. That is, the venous system serves as a reservoir of blood upon which the cardiovascular system can draw at times of increased demand for arterial blood delivery to active tissue. At rest the venous system typically accounts for $65 \%$ of the total blood volume, and is influenced by several factors including nutritional status, pharmacologic intervention, morbidity of various disease states, and emotional or physical arousal (e.g. physical activity, exercise). Invariably, it is this latter determinant, physical exertion that has a profound influence on venous function. During exercise, venous return increases, thereby facilitating increases in cardiac output, and shifting a greater percent of blood volume to the arterial side.

While the importance of venous return on cardiac output for the purpose of enhanced delivery of oxygen and other humoral factors is well documented, the venous system also plays a crucial role in the removal of blood and waste products from exercising muscle. This removal of metabolic by-products plays a potentially important role in sustaining physical activity over long periods. This aspect of venous return has, for the most part, been underinvestigated with respect to exercise tolerance. and therefore functional ability. Yet, it may be of particular relevance with respect to function in 
patients such as those with congestive heart failure (CHF), hypertension, chronic venous insufficiency (CVI), and peripheral vascular disease (PVD).

Despite the lack of success with these approaches, the potential role of venous dysfunction in patients with diseases mentioned above has been largely unexamined. It is unclear what role the venous system may play in the underlying causes associated with many of these diseases. Therefore, efforts directed at unveiling the role of venous system function in the appearance of functional limitations imposed by signs and symptoms of cardiorespiratory limitations may assist in developing improved treatment strategies for cardiovascular-related conditions. Such treatment strategies have focused on arterial dysfunction, without regards to these effects on venous dysfunction. Therefore, the role of the venous system has been, to a large extent underestimated and underinvestigated, in its role concerning cardiovascular disease. The success of systemic investigation of venous function hinges on the availability of valid measurement techniques. An important characteristic of the validity of a measurement technique is its reliability.

Overall reliability of the SGP method has been reported to range from $6 \%$ to $28 \%$ (Corbally \& Brennan, 1990; LeJemtel, Katz, Jondeau \& Solomon, 1992). One particular study conducted by Pallares, Deane, Baudouin and Evans, 1994, found SGP, when used to measure blood flow within-day measures at rest and during conditions of increased cardiac output, to be highly reproducible compared to Doppler ultrasound ( 0.45 and 0.94 $\mathrm{ml} \backslash 100 \mathrm{ml}^{-1}$ tissue $\backslash \mathrm{min}^{-1}$ respectively). Additionally, studies conducted by Romano and Gizdulich, 1980; Altenkirch, Fransson and Koch, 1989, as well as Altenkirch, Koch and Koralewski, 1990, have found the SGP technique to be more reproducible for within-day measures than between-day measures. Accordingly, long-term reproducibility of 
measures has not been well established, with the limited data available raising some question as to the long-term stability of these readings. Gizdulich and Michelutti, 1983, suggest that venous outflow measures may be influenced by venous occlusion pressure, and less by muscular tone, flow sampling rate and the length of the venous occlusion.

The purpose of this study was to examine venous vascular function using EC-5R

plethysmography system (Hokanson, Sumner \& Strandness, 1999). More specifically, the objective of this study was to evaluate the reliability, using strain gauge plethysmography (SGP), of forearm blood flow during rest and immediately following ischemia.

\subsection{Clinical Significance}

The venous system serves many important functions in the body such as selective barrier function, angiogenesis, postcapillary resistance, synthesis of bioactive substances and more importantly, a conduit or collection system with one-way valves that help regulate the distribution of blood volume. Due to the distensibility of veins, the venous side contains $65 \%$ of the total blood volume at rest and during activity is crucial for the removal of blood and waste products from exercising muscle. The perfusion of muscle tissue as well as the removal of by-products is therefore an important aspect in organ $\backslash$ system performance (Wecht et al., 2000). Several factors influence venous function including diet, exercise, disease, and pharmacotherapy (Rizzi et al., 1998). However, in comparison to arterial inflow, relatively few studies have examined venous function. The majority of data, although scarce, have examined the reproducibility of SGP in healthy young individuals at rest and following ischemia (Wecht et al., 2000). Despite the lack of consensus regarding the stability of the venous measures obtained from SPG, it is still used for the evaluation of blood flow due to its simple and economical method, and the 
potential exists for SGP to contribute to our understanding of venous function. However, before this technique can be employed to evaluate the efficacy of various treatment strategies on venous function, more work must be done to establish the reliability of this technique and to identify potential sources of variation on venous function. To this end, venous system structure and function in health and disease states was reviewed in order to more fully understand the potential sources of variation on venous function. The methods section that followed included a presentation of the evidence regarding the present understanding of the reliability of venous function measures. 


\section{Chapter 2}

\section{Venous System}

\subsection{Structure and Function of Veins}

The blood vessels of the body form a closed delivery system that begins and ends at the heart. If stretched out in a line, the 100,000 miles of blood vessels of an averagesized adult would circle the earth four times. The body's blood vessels can hold nearly 20 liters of blood even though the actual total blood volume is approximately 5 liters (McKardle, Katch \& Katch, 1996). The three major types of blood vessels consist of arteries, capillaries and veins, that latter of which is the focus of this review. Like arteries, veins contain three distinct tunics, but their walls are thinner and their lumens larger than those of arteries. The innermost tunic, which is in intimate contact with blood, is called the tunica intima. This tunic contains endothelium that lines the lumen of all vessels. The endothelial lining forms a slick surface that minimizes friction as blood moves through the vessel lumen. The tunica media is the middle, thicker layer composed of connective tissue with elastic fibers, which can withstand longitudinal and circumferential stress. This layer allows veins to tolerate changes in pressure and flow by providing elastic recoil and muscular contraction (Sansivero, 1998). The tunica adventitia, the outermost layer of the vessel wall, is composed largely of loosely woven collagen fibers that protect the blood vessel wall and anchor it to surrounding structures 
(Marieb, 1992). In very large vessels, this layer may be thicker than the tunica media and may contain nutrient blood vessels (Sansivero, 1998).

Veins play an important role in many physiological functions such as conduits that regulate the distribution of blood volume. Since $65 \%$ of the blood volume is found in the veins at any one time, veins are called capacitance vessels or blood reservoirs. Some organs have a large capacity for storing venous blood. The most significant blood reservoirs and their estimated capacities include: spleen (150ml), liver (200-300 ml), large abdominal veins $(300 \mathrm{ml})$, and heart and lungs $(50-100 \mathrm{ml}$ and $100-200 \mathrm{ml})$. Quick recruitment of these stores compensates blood loses of as high as $20-25 \%$ of the total blood volume while maintaining adequate arterial pressure and tissue perfusion. The blood reservoirs not only quickly release but also rapidly accumulate blood. If central venous pressure increases, the liver accumulates a substantial amount of blood, doubling its capacity, thus functioning as a primary Hemodynamic buffer (Monos, Berczi \& Nadasy, 1995). Blood draining from capillaries is collected by venules, small veins that merge to form larger veins that eventually empty into the great veins, superior and inferior vena cava, that converge on the heart. The capillaries feed deoxygenated blood into the venules or small veins.

Since blood pressure within veins are very low (8-10 mm HG) and they can be thinner walled than arteries (80-100 mm HG) without danger of bursting (Archie \& Green, 1990). However, low-pressure conditions demand special adaptations to help return blood to the heart. The large-diameter lumens of veins as well as valves that prevent back flow are another adaptation. Valves are most abundant in the veins of the limbs, where the upward flow of blood is opposed by gravity. Venous valves are formed 
from folds of the tunica intima, and resemble the semilunar valves of the heart in both structure and function (Marieb, 1992). Most often, valves are paired and face one another, but occasionally there will be one or three flaps. When blood flows in a retrograde fashion, the valve sinuses close, preventing backflow (Sansivero, 1998).

Venous flow is influenced by several factors. Because veins are on the lowpressure side, they are easily compressed by the smallest of muscle contractions (muscle pump) or even by minor pressure changes within the chest cavity with breathing and contain flap-like valves that permit a one-way flow toward the heart. The alternate compression and relaxation of the veins, as well as the one-way action of their valves, provide a "milking" action, which removes wastes and propels blood back toward the heart. The smaller veins in the lower portion of the body empty into the inferior vena cava and return blood back to the right atrium. Deoxygenated blood from the upper portion of the body empties into the superior vena cava and joins the inferior vena cava at the heart level. Blood from the upper and lower portion of the body enter the right atrium and descends into the right ventricle, where it is then pumped through the pulmonary artery to the lungs. The oxygenated blood then returns to the left side of the heart through the pulmonary veins to begin another pass through the body (McKardle et al., 1996; Sansivero, 1998).

Veins also contribute to maintenance of filling pressure of the heart. prerequirement for such regulation is that the vascular bed of appropriate venous tone should be adequately filled with blood. During stress, such as exercise, both ventricles can change within a wide range; therefore an adequate amount of venous return to the 
right heart is needed to maintain filling pressure, providing adaptation to the changing cardiac output (Monos et al., 1995).

Changes in body position greatly influence the hydrostatic loads placed on the blood vessels. the brain blood supply or to orthostatic edema in tissues. Local preventative mechanisms such as muscle pump and venivalvular pump help to increase orthostatic tolerance (Monos et al., 1995).

Venules determine the output resistance of the microcirculatory bed due to changes of their cross-sectional area. Other factors determining the output resistance of the microcirculatory vessels are the time-, flow-velocity-, and diameter-dependent changes in blood viscosity. The ratio between the pre- to postcapillary resistance determines the hydrostatic pressure of the blood in the exchange vessels and the filtration-resorption balance (Monos et al., 1995).

The venular part of the microcirculation is the typical site of angiogenesis, usually due to enhanced metabolic requirements. It is thought that the mechanism responsible may be due to minor damage to the basal membrane by the endothelium-derived proteinases, which is followed by the growth of a capillary sprout (Monos et al., 1995).

Evidence exists that the vein wall synthesizes bioactive substances such as NO via stimulation of muscarinic, thrombin and a2-adrenergic receptors, prostacyclin and prostaglandins. The EDRF-induced relaxation provides reciprocal control of the vascular tone, since blood vessels only posses vasoconstrictor fibers and have no dilatory innervation. A variety of vasoactive substances such as acetylcholine, angiotensin, ATP, bradykinin, histamine, serotonin and thrombin induce EDRF-mediated relaxation. 
Stimuli, such as pulsatile flow, cause relaxation by increasing endothelial shear stress with subsequent release of EDRF. A growing body of literature suggests the existence of a basal secretion of EDRF, which reduces baseline venous tone (Glick, Gehman \& Gascho, 1993). In addition, EDRF in synergism with prostacyclin plays an important role in the inhibition of platelet aggregation and adhesion to the endothelial wall. Endothelin, which causes smooth muscle contraction, may also trigger synthesis of $\mathrm{EDRF}$ and prostacyclin through the activation of $\mathrm{ET}_{\mathrm{b}}$ receptors (Masaki, Kimura, Yanagisawa \& Goto, 1991). Other vasoactive substances such as hyperpolarizing factor, histamine, and vasoconstrictor and vasodilator metabolites of arachidonic acid are also synthesized in endothelial cells. Endothelial cells are also important in the synthesis of antioxidants, conversion of angiotensin I to angiotensin II as well as the formation of vascular wall matrix substances (collagen, elastin, glycoproteins and proteoglycans).

Certain lymphoid organs, such as lymph nodes, contain specific receptors (homing receptors) mediated via addressins found in endothelial venules, which exhibit a special barrier function. These circulating effector lymphocytes leave the vasculature via high endothelial venules distribute circulating effector lymphocytes due to stimuli such as inflammation (Wu, Jalkanen, Streeter \& Butcher, 1988).

Local hemodynamic, endothelial and biochemical factors such as arachidonic acid -derived substances control the interaction of polymorphonuclear leukocytes (PMNLs) and the endothelial surface. A substantial part of PMNLs adhere to the endothelium and is typical for venules where linear velocity and thus the shear rate are low. Some PMNLs return to the circulation, while others penetrate into the interstitial space or remain adhered to the endothelial surface, rolling in the direction of the blood flow. The cells 
move relatively slow and a balance is developed between PMNLs leaving the vascular bed and those returning to the circulation (Bienvenu \& Granger, 1992). Cooperation also exists between the PMNLs and the endothelium surface in bactericide functions and inflammatory reactions (Monos et al., 1995).

Both arterial and venous endothelium inhibits platelet aggregation. However, the thromboembolic reactions of the venules are of shorter duration compared with the arterioles. Platelet distribution differs between venules and platelet density is significantly lower, especially in the deep lower limb vessels such as the soleus and femoral vein endothelium (Woldhuis, Tangelder, Slaaf \& Reneman, 1992). This may explain the pathomechanism of venous thromboembolism, help in the prevention of venous diseases and aid in the success of vein graft surgery.

Veins may also aid in special regional functions. For example, the buccal part of the facial vein exhibits temerature-dependent myogenic tone and contributes to the cranial thermoregulation and emotional blushing (Mellander, Anderson, Afzelius \& Hellerstrand, 1982). Veins may serve a venous pressure buffer function in the regulation of intracranial pressure due to increases in cerebral blood volume. The proximal segments of the caval and pulmonary veins, close to the heart, may also exhibit pacemaker activity and under certain pathological conditions, can serve as the site for ectopic beats. When an individual is in the upright position, the internal jugular vein serves to regulate pressure of the cerebral sinuses and intracranial pressure. Skin has a rich subcutaneous plexus, which contain a2-adrenoreceptors, for conservation or loss of heat in thermoregulation (Flavahan, 1991). The portal vein of the liver plays a dual role 
of a collector and distributor in the splanchnic circulation. In the kidney, the peritubular venous plexus involved in tubular absorption and secretion processes.

\subsection{Biomechanical Control}

The active and passive biomechanical control of venous tone is essential for functions under normal and pathophysiological conditions. The incidence of vein diseases is extremely high, in many countries exceeding that of arterial pathology by almost an order of magnitude (Ibrahim, MacPherson \& Goldhaber, 1995).

The involvement of different biomechanical anomalies of the vein wall may contribute substantially to the development and maintenance of arterial hypertension. A three-dimensional stress-strain relationship has been used to identify certain biomechanical characteristics thought to control venous tone (Fung \& Liu, 1992). Due to the much smaller wall thickness-to radius-ratio, as well as higher distensibility in the low transmural pressure range, veins can greatly exceed the stress of arteries measured at similar pressure loads. However, the breaking pressure for some veins is surprisingly high $(2,873 \mathrm{~mm} \mathrm{HG})$ (Archie et al., 1990). It is thought that mechanical properties of the vessel wall such as collagen, elastin and its smooth muscle tone greatly affect the pressure-volume characteristics. At normal physiological conditions, collagen is probably secondary in Hemodynamic stress-bearing function of the vein wall compared with smooth muscle and elastin (Monos et al., 1995).

In different physiological states, such as exercise, biomechanical properties of veins can change in an adaptive manner. Increases in distensibility and lumen thickness of veins are seen in long-term exercise due to repeated exposure to shear stress and cardiac output. Additionally, decreases in distensibility and elasticity are seen in the 
elderly compared to younger individuals (Gascho, Fanelli \& Zelis, 1989). The size of the body also affects the vein competence and is correlated with the inner diameter of the femoral vein (Mortensen, Talbot \& Burkart, 1990).

The available information on the local regulation of the systemic venous tone is very limited with the exception of a few vessels. Many reports on the transmural pressure induced (stretch) venous tone response are inconclusive. However, it is emphasized that small increases of smooth muscle tension due to pressure may significantly reduce the passive dilation of the otherwise highly distensible vessels exposed to the pressure. For example, increases in smooth muscle tension due to increases in gravitational load could significantly enhance orthostatic tolerance of an individual. On the other hand, pathologically altered reactivity of the systemic veins may induce changes, which can lead to the development and maintenance of cardiovascular diseases (Monos et al., 1995).

Intraluminal pressure-induced acute myogenic tone of smooth muscle may be higher in certain vessels and this myogenic response to intraluminal pressure contains a static and dynamic component. It is thought that elevated activity of protein kinase $\mathrm{C}$ in smooth muscle may be one cellular mechanism resulting in increased myogenic reactivity through the activation of stretch-sensitive nonselective cationic channels in the smooth muscle membrane (Davis, Donovitz \& Hood, 1992).

Evidence also suggests that apart from the intraluminal pressure, flow rate can also affect venous tone independently of the pressure (Bevan \& Joyce, 1990). Flowdependent vasodilation, caused by increases in shear stress, requires intact endothelium for the synthesis of ATP, substance $\mathrm{P}$, and Ach as well as $\mathrm{CA}^{2+}$ influx into the endothelial cells, changes in extracellular $\mathrm{NA}^{+}$and its membrane gradient (Bevan \& Siegel, 1991; 
Bevan \& Joyce, 1993). The flow-dependent contraction related to $\mathrm{CA}^{2+}$ influx into the smooth muscle cells probably differs from the calcium channel involved in the pressurelstretch response and is less endothelium dependent (Henrion, Klaagen \& Bevan, 1992). Special $\mathrm{NA}^{+}$and $\mathrm{CA}^{2+}$-binding glycosaminoglycan polyanions in the extracellular matrix and plasma membranes of the endothelium and smooth muscle cells are thought to be primary flow sensors (Bevan \& Joyce, 1992, 1993).

\subsection{Local Control}

\subsubsection{Metabolic Control}

In systemic circulation, metabolic control is reduced or elevated, depending on the metabolic needs of the tissues. Tissue perfusion induces a compensatory dilation or contraction of resistance vessels, which in turn, elicits a regulatory decrease or increase in capillary blood flow. Several mechanisms for these changes have been suggested and include metabolites that may exert their action directly on vascular smooth muscle cells, or they can locally modulate norepinephrine release from sympathetic nerve endings, or the sensitivity of adrenergic receptors (Johnson, 1986). The contribution of venular flow resistance in the systemic circulation is only a fraction of the total resistance, however, the contractile resistance and properties of venules significantly contribute to capillary hydrostatic pressure and to the control of blood volume (House \& Johnson, 1986). Blood in small veins is adjusted in accordance with the tissue fluids with respect to its $\mathrm{Po}_{2}, \mathrm{Pco}_{2}$, $\mathrm{pH}$ and adenosine and phosphate content. Contractility to these metabolic substances seems to be less sensitive in larger veins compared to small ones and may have important pathological implications (Honig, Gayeski, Clark \& Clark, 1991). Variable amounts of data indicate that there are regional differences in the metabolic control of veins. Studies 
have found that venules take part in the vasodilatory processes during and after muscle work. The venules of the mesenteric organs contribute mainly to the increases in blood volume whereas the venules in the skeletal muscle contribute only minutely to increases in flow. The response of venules seems to be workload dependent, responding somewhat slower than arterioles. Several mechanisms include an altered $\mathrm{Po}_{2}$ through oxidative phosphorylation, release of vasoactive substances as prostaniods or leukotrines, release of adenosine, $\mathrm{ADP}$ or $\mathrm{ATP}$, or $\mathrm{Pi}$, a decrease local $\mathrm{pH}$ as a result of increased $\mathrm{Pco}_{2}$ or lactate production, an increase in local $\mathrm{K}^{+}$or local osmolarity (Marieb, 1992; Monos et al., 1995).

\subsubsection{Oxygen}

The venous system is more capable of forming lactate from pyruvate and seem to be better adapted to anaerobic glycolysis that arteries (Malmqvist, Arner \& Uvelius, 1991). Veins of the systemic circulation respond to hypoxia in a different manner. For example, in coronary vein segments exposed to acute hypoxia induced an endotheliumdependent contraction. Pulmonary venules responded to hypoxia with a profound contraction whereas placental veins showed hypoxic relaxation and reoxygenation contraction (Figueroa, Omar, Tejani \& Wolin, 1993). The mechanism of the observed effects of lowered $\mathrm{Po}_{2}$ remains unclear. A reduction in the number of action potentials in connected with reduced periodic contractions observed during hypoxia. Also a substantial amount of lactic acid release has been observed in normoxic conditions whereas a decrease in tissue oxygen consumption can be observed with an increase in lactic acid production. The intracellular content of phosphocreatine is decreased, while that of ATP is maintained, suggesting that the rate of anaerobic glycolysis is elevated in hypoxia. 
Other mechanisms such as decreased $\mathrm{Ca}^{2+}$ sensitivity of the vein wall as well as a decrease in the release of prostaniods and leukotrines have been suspected to induce hypoxic contractions (Soloviev \& Basilyuk, 1993).

\subsubsection{Adenosine}

Adenosine is a powerful vasorelaxant agent and in many vascular beds is thought to be one of the main factors mediating adjustments of resistance vessels to metabolic needs of the tissue. Adenosine relaxes veins in a concentration dependent manner and in addition to its effect on smooth muscle, it has also been reported to increase venular permeability (Johnson, 1986). Two receptors, in mammals, have been identified as powerful vasoactive agents and whose physiological function may contribute to the metabolic control of vessels. The presence of P1purinoceptors has been shown to mediate vasoconstriction by inhibiting the release of NE from adrenergic nerve terminals, whereas P2 purinoceptors mediated contraction in response to ATP (Mathie, Alexander, Ralevic \& Burnstock, 1991).

\subsection{4 pH, Pco $\mathrm{P}_{2}$, Lactate, Potassium and Osmolarity}

Decreased $\mathrm{pH}$, elevated $\mathrm{Pco}_{2}$, and increased lactate release are thought to key metabolic vascular caliber adjustments in many tissues (Johnson, 1986). Lowered pH and elevated $\mathrm{Pco}_{2}$ have been found to decrease contractility in veins. For example, a pH shift from 7.6 to 6.9 inhibited the contractile response to NE, serotonin and prostaglandin in human hand veins (Arner \& Hogestatt, 1991). In conditions were $\mathrm{Pco}_{2}$ is low, lactate may be released not only released from surrounding tissues but from the vein wall itself and is better suited for the transformation of pyruvate into lactate than arteries (Malmqvist et al., 1991). Potassium as well as increased osmolarity is also thought to be involved in the 
metabolic control of circulation in certain tissues. Their concentrations are released from the intracellular space and exert a direct effect on venous tone (Johnson, 1986).

\subsection{Ionic Control}

\subsubsection{Sodium}

Transport systems regulating the distribution of sodium across cell membranes have been observed in the venous wall. These systems are important in adjusting membrane potential, intracellular calcium, intracellular $\mathrm{pH}$ and cell volume (Monos et al., 1995).

The sodium pump in vascular smooth muscle plays a very similar role as it does in other tissues, and is a key regulatory factor in the regulation of transmembranes $\mathrm{NA}^{+}$ as well as $\mathrm{K}^{+}$concentrations and membrane potential. However, vascular smooth muscle cells have an extremely low number of $\mathrm{NA}^{+}$pump sites per cell when compared with cardiac and skeletal muscle. Within the vascular system it appears that these pump sites may play a greater role in the maintenance of the resting membrane potential in venous rather than arterial smooth muscle cells (Allen, Kahn \& Navran, 1986). A number of neurohumoral and vasoactive factors, including adrenergic agents, stimulate the $\mathrm{NA}^{+}-\mathrm{K}^{+}$ pump in smooth muscle. The stimulation of a-adrenergic receptors is thought to cause an increase in $\mathrm{NA}^{+}$influx, due to the activation of a $\mathrm{NA}^{+} \backslash \mathrm{H}^{+}$exchanger and is dependent to a large extent on aerobic glycolysis (Hellstrand, Jorup \& Lydrup, 1984). Venous smooth muscle tone and reactivity may not only be influenced by inhibition of the $\mathrm{NA}^{+}-\mathrm{K}^{+}$pump of smooth muscle cells but also by inhibition of the $\mathrm{NA}^{+}-\mathrm{K}^{+}$pump of adrenergic nerve endings. 
The active $\mathrm{NA}^{+} / \mathrm{CA}^{2+}$ exchanger may be functionally more important in venous that in arterial smooth muscle. The NA ${ }^{+} / \mathrm{CA}^{2+}$ exchanger regulates contractility by moving $\mathrm{CA}^{2+}$ out of the cell, at the expense of $\mathrm{NA}^{+}$influx, which is then removed by the $\mathrm{NA}^{+}-\mathrm{K}^{+}$pump (Monos et al., 1995). Additionally, other mechanisms such as the $\mathrm{NA}^{+} / \mathrm{H}^{+}$ exchange system also plays an active role in maintaining intracellular $\mathrm{pH}$ homeostasis by using the electrochemical energy of the sodium gradient existing across the cell membrane in which cells regulate $\mathrm{H}^{+}$extrusion and $\mathrm{NA}^{+}$influx (Escobales et al., 1990). Other channels such as the $\mathrm{NA}^{+}-\mathrm{K}^{+}-\mathrm{Cl} \underset{\underline{\underline{E}}}{-}$ ansport system may govern the resting membrane potential andlor cell volume in vascular smooth muscle (Brock, Brungnara, Canessa \& Gimbrone, 1986).

The distribution of sodium within the venous smooth muscle is fairly uniform (Monos et al., 1995). Decreases in sodium content of vascular smooth muscle has been shown to both enhance and attenuate contractile responses in the presence of vasoactive agents or nerve stimulation, thereby playing an important role in the pathophysiology of hypertension. Although the direct link between sodium and hypertension is not clear, it appears to be specific to the cardiovascular system. Circulating factors such as angiotensin II may contribute to the accumulation of excess sodium in vascular tissue (Simon, 1978). Additionally, this accumulation in the extracellular space of arteries and veins may promote vasoconstriction in hypertension. In the case of veins, tissue swelling may reduce distensibility and is thought to facilitate the vasoconstrictor response by mediating $\mathrm{NA}^{+}$influx (Simon, 1990). 


\subsubsection{Potassium}

Various actions of $\mathrm{K}^{+}$are thought to directly and indirectly play important roles in the alteration in membrane action potential directly or through the electrogenic $\mathrm{NA}^{+}-\mathrm{K}^{+}$ pump, alterations in cell membrane permeability and intracellular $\mathrm{NA}^{+}$, or modulation of NE release by sympathetic nerves. Potassium has various effects on the vascular system in a concentration dependent manner. For example, moderate amounts of $\mathrm{K}^{+}(5-10 \mathrm{mM})$ cause dilation in vessels, whereas the response to further increases in $\mathrm{K}^{+}(>15 \mathrm{mM})$ was constriction, due to the depolarization and activation of voltage-dependent calcium channels (Wali, Greenridge \& Tugwell, 1988). Drugs such as potassium channel openers are used to treat hypertension and angina by causing dilation in arteries and veins through an increase in $\mathrm{K}^{+}$permeability and hyperpolarization. Other potassium channels such as calcium-activated potassium channels are among the most commonly existing channels in various tissues that are activated through increases in intracellular calcium. On venous smooth muscle, three types exist and are referenced according to the difference in their conductance (large, medium and small). Additionally, various calcium-dependent channels identified as delayed rectifier, background and transient potassium currents and is responsible for the regulation of membrane potential (Beech \& Bolton, 1989). However, these channels have been studied extensively in rabbit venous smooth muscle and may not be applicable to that of human venous tissue.

\subsubsection{Calcium}

Calcium plays an important role in the initiation of contraction in smooth muscle. Two mechanisms that activate calcium involve two $\mathrm{CA}^{2+}$ pools: the extracellular pool where influx and efflux are regulated by the sarcolemma and the intracellular pool, 
regulated mainly by the sarcoplasmic reticulum (Monos et al., 1995). Calcium influx from the extracellular pool is mediated through stretch activated $\mathrm{CA}^{2+}$ channels, whereas the release of $\mathrm{CA}^{2+}$ from the intracellular pool is linked to binding of the second messenger to receptors in the sarcoplasmic reticulum (Kobayashi, Gong, Somilyo \& Somilyo, 1991). Additionally, it has been shown that $\mathrm{CA}^{2+}$ is not evenly distributed within venous smooth muscle and may contribute to the calcium-independent part of the membrane potential. Intracellular concentration of ATP and other adenine nucleotides was also shown to influence the release of $\mathrm{CA}^{2+}$ from the intracellular store, causing a concentration-dependent influence on venous tone (Papageorgiou \& Morgan, 1990).

Only a few types of calcium channels have been characterized in venous smooth muscle. One type was activated by small depolarizations and inactivated quickly, whereas the other required stronger depolarizations for activation and inactivated more slowly. Calcium channels blockers are among the most frequently used drugs in clinical practice. Studies on small arteries and veins have observed that calcium channel blockers have more pronounced effects on the arterial than the venous side of the circulation (Sjoberg, Andersson, Norgren \& Steen, 1987).

Many venoactive agents utilize $\mathrm{CA}^{2+}$ in their actions and may originate from the extracellular or intracellular stores. For instance, a-adrenergic stimulation causes an increase in vascular tone through increases in $\mathrm{CA}^{2+}$ as well as myosin light-chain phosphorylation (Aburto, Lajoie \& Morgan, 1993). Additionally, mobilization of $\mathrm{CA}^{2+}$ during endothelin-induced contractions depends on extracellular $\mathrm{CA}^{2+}$ stores in arteries, whereas intracellular $\mathrm{CA}^{2+}$ stores are important in veins (Monos et al., 1995). Also, rises in $\mathrm{CA}^{2+}$ facilitate the activation of histamine and Vasopressin in venous smooth muscle. 
In Addition to venous smooth muscle cells, venous endothelial cells also utilize calcium for their different functions. The biosynthesis and release of EDRF in veins is dependent on $\mathrm{CA}^{2+}$ entry into specific $\mathrm{CA}^{2+}$-permeable channels (Tsukahara, Gordienko \& Goligorsky, 1993). The release of prostaglandin and thromboxane are also associated with $\mathrm{CA}^{2+}$ mobilization from intracellular stores (Baron et al., 1993).

Endothelial cells are subjected to shear stresses and normal pressure by blood flow. These forces elicit many physiological responses in endothelial cells such as secretion of prostacyclin and EDRF, and an increase in $\mathrm{CA}^{2+}$. Changes in flow may induce either dilation or constriction depending on the level of tone in smooth muscle cells (Monos et al., 1995). $\mathrm{CA}^{2+}$-permeable stretch-activated channels have been described in arterial endothelial cells as well as venous cells. These stretch-activated channels cause a rapid increase and entry of $\mathrm{CA}^{2+}$ from intracellular stores that are associated with stretch-induced contraction (Naruse \& Sokabe, 1993).

Calcium plays an important role, not only in the initiation of contraction, but also in other functions that help to regulate venous smooth muscle tone. Therefore it is thought that alterations in $\mathrm{CA}^{2+}$ metabolism and calcium channels may play a role in the development and maintenance of hypertension. For instance, genetic alterations in certain calcium channels, appearing on the venous side, could contribute in the development of increased blood pressure (Hermsmeyer, 1991).

\subsubsection{Magnesium}

The majority of studies examining the effects of $\mathrm{Mg}^{2+}$ on the vascular smooth muscle have been done on arteries, although a few studies have conducted on veins, too (Chiavarelli et al., 1992). Magnesium is a significant natural $\mathrm{CA}^{2+}$ antagonist, inhibiting 
the voltage-dependent and receptor-dependent channels. Reductions in $\mathrm{Mg}^{2+}$ concentration enhance $\mathrm{CA}^{2+}$ influx into the vascular smooth muscle cells leading to a consequent increase in venous tension and reactivity (Altura \& Altura, 1984). For example, decreased $\mathrm{Mg}^{2+}$ concentrations of human arteries as well as veins caused an increase in basal tension and potentates the contractile response of the vessels to certain hormones. Conversely, high concentrations of $\mathrm{Mg}^{2+}$ resulted in vasodilation of veins (Chiavarelli et al., 1992). Total withdrawal of $\mathrm{Mg}^{2+}$ had a reciprocal effect on the smooth muscle tone, starting with an endothelium-dependent and calcium-dependent dilation followed by a sustained endothelium-independent contraction. $\mathrm{Mg}^{2+}$ is therefore an important contributor in regulating venous tone and protecting the endothelium against spasm induced by a reduced $\mathrm{Mg}^{2+}$ concentration in the pathophysiological range (Szabo et al., 1992).

\subsubsection{Chloride}

In the past, scientists have neglected the importance of chloride in vascular smooth muscle. Recent research has estimated that chloride concentrations in vascular smooth muscle is much higher than those found in skeletal and cardiac muscles and is thought to be important in many steps of the excitation-contraction coupling in muscle (Bretag, 1987). Chloride is transported across the cell membrane by several different mechanisms, which include cotransporters, exchangers, and conductive channels. These mechanisms are thought to be involved in actions such as cell volume regulation, and anion exchanges for the regulation of intracellular $\mathrm{pH}$ (Zhang, Carella, Altura \& Altura, 1991). Several types of chloride channels have been identified, in mammals, according to their conductance and are activated by the release of $\mathrm{CA}^{2+}$ from intracellular stores and 
through voltage-dependent calcium channels. The action of $\mathrm{Cl}^{-}$is suggested to contribute significantly in the regulation of arterial and venous tone and contractility (Queroy \& Verdetti, 1992).

\subsection{Hormonal Control (Constrictor Agents)}

\subsubsection{Angiotensin II}

Angiotensin-converting enzyme (ACE) or kininase II, angiotensin and angiotensin receptors have been shown to exist in vascular tissue. In fact angiotensin I has been shown to convert to angiotensin II (ANG) in the human hand vein (Mizuno et al., 1991). However there is an inconsistency in the literature to support single and $\backslash$ or multiple angiotensin receptors in vascular smooth muscle (Li et al., 1996). The dominant venoactive effect of ANG II in human veins is constriction due to sympathetic nerve stimulation via an increased release of NE from the nerve terminals in smooth muscle (Webb, Benjamin, Cockcroft \& Collier, 1989). Certain pathophysiological conditions alter the effect of ANG II on the venous system. For example, contractile responses to ANG II are increased in the forearm veins of hypertensive patients compared to healthy

counterparts (Sudhir et al., 1990). Responses to ANG II in hypertension may increase the permeability of venules and veins to plasma components, which may be an additional pathogenic factor.

\subsubsection{Neuropeptide $Y$}

Neuropeptide Y (NPY) is a potent contractile agent found in human vessels such as mesenteric, saphenous and uterine veins (Fried \& Samuelson, 1991; Luu et al., 1992). NYP is thought to exert both post-junctional (vasoconstrictor effects) and pre-junctional (inhibition of NE release) effects. Neuropeptide Y not only responds to nerve stimulation 
but also to a variety of vasoconstrictor agents and is coreleased with NE in an abundance of sympathetic fibers. NYP plays a functional role in neurotransmission, due to presynaptic site of action, by inhibiting transmural nerve stimulation evoked by $\mathrm{NE}$ efflux (Daly, Roberts, Ruffolo \& Hieble, 1988).

In addition to the direct vascular effects, NYP also upregulates the adhesiveness of certain veins to leukocytes and may serve as modulators of not only the neuromuscular unit but also the interaction of endothelial cells with leukocytes (Sung, Arleth \& Feuerstein, 1991).

\subsubsection{Neurotensin}

The portal vein of certain mammals is the only vessel on which Neurotensin effects were studied. Neurotensin increased basal tension, frequency and peak phasic contraction (Monos et al., 1995).

\subsubsection{Vasopressin}

Vasopressin (AVP) is a vasoconstrictor peptide that has an effect on a variety of veins. AVP was shown to induce contraction in the human chorionic plate where as the mesoappendix vein did not respond. The action of AVP is thought to be the result of in an increase of $\mathrm{CA}^{2+}$ in smooth muscle cells from intracellular stores. Although AVP has exerts direct venoconstrictor effects, actual circulating levels of AVP seem to be important in the regulation of vascular capacitance through changes in autonomic nervous function (Martin \& McNeil, 1991). The effect of AVP is important in the treatment of hemorrhage in cirrhotic patients in which blood velocity and blood flow are decreased primarily due to arteriolar constriction. Additionally, actions of AVP may be enhanced in certain pathological conditions such as left ventricular dysfunction and heart 
failure in which the inhibition of AVP causes venodilation and a reduction in mean circulatory filling pressure (Raya, Gay \& Goldman, 1990).

\subsection{Relaxing Agents}

\subsubsection{Atrial Naturetic Peptide}

Atrial Naturetic peptide (ANP) is a far more effective dilator in arteries and arterioles than veins. The relaxing effect produced by ANP may depend on the contribution of alpha-1, alpha-2 and intrinsic vasoconstrictor components to the level of smooth muscle tone (Faber, Gettes \& Gianturco, 1988). The majority of studies use animal subjects with only few studies showing no effect of ANP on human peripheral venous tone. However, ANP is shown to increase venous distensibility in human forearm veins probably through inhibition of angiotensin- or thrombin-induced secretion of endothelin (Ando et al., 1992).

\subsubsection{Calcitonin Gene-Related Peptide}

Calcitonin gene-related peptide (CGRP) is a sensory Neuropeptide that has the ability to produce long-lasting dilation in diverse parts of the vasculature such as human mesenteric and saphenous veins (Luu et al., 1992). The dilatory effects of CGRP may be exerted through the release of endothelial vasorelaxant substances such as prostacyclin and adenylate. Subsequently, these endothelium-dependent responses to CGRP may vary from vein to vein.

CGRP also functions as a peptide that stimulates vascular proliferation that is associated with cAMP formation. Therefore, CGRP may be important in the formation of new vessels during physiological stress and pathophysiological stress such as ischemia (Haegerstrand et al., 1990). 


\subsubsection{Vasoactive Intestinal Polypeptide}

Vasoactive intestinal polypeptide (VIP) induces responses in veins containing VIP neurons in the nonadrenergic noncholinergic vasodilation (Hardebo, Kahrstrom, Owman \& Salford, 1987). However, some veins such as the saphenous veins are less sensitive than internal mammary veins possibly because of the lower receptor density and are thought to be secondary to hypertension (Luu et al., 1993).

\subsection{Agents with Constrictor and Relaxant Effects}

\subsubsection{Bradykinin}

Bradykinin $(\mathrm{BK})$ and related kinins are potent vasodilators found in the majority of peripheral vascular beds, however they do contract some arteries and most veins. This is due to two types of BK receptors, which exhibit various responses in arterial and venous smooth muscle. $B_{1}$ receptors mediate contraction of arterial smooth muscle while $\mathrm{B}_{2}$ receptors are involved in the relaxation of arteries and increase vascular permeability. Both $\mathrm{B}_{1}$ and $\mathrm{B}_{2}$ receptors contract venous smooth muscle due to intracellular and extracellular $\mathrm{CA}^{2+}$ mobilization (Takata et al., 1990). Additionally, mechanisms, which may explain BK-induced vasodilation veins, may involve mediators such as EDRF and prostacyclin (Dachman, Ford, Blaschke \& Hoffman, 1993).

\subsubsection{Eicosanoids}

Venous tissues, along with other tissues, produce and release various types of prostaniods. Prostanoids such as prostacyclin and thromboxane make up a large percentage of metabolites found in veins (Monos et al., 1995). The action of prostanoids has different effects on the vasculature with contracting effect in some vascular beds and relaxation in others. Prostacyclin is shown to cause relaxation in human hand veins 
whereas thromboxane exhibited a contractile response in the saphenous vein, which may be due to thromboxane-specific receptors that mediate a rise in calcium (Kent et al., 1993).

Different humoral agents can modify vasoactive prostanoid production of the vessel wall. For example, norepinephrine increases the release of both prostacyclin and thromboxane, whereas Vasopressin increased only thromboxane and BK increased only prostacyclin release. Additionally, plasma itself stimulates prostacyclin production of certain veins (Brunkwall et al., 1989).

Mechanical factors have also been shown to affect vasoactive prostanoid in the control of venous smooth muscle tone and thrombus formation. For instance, an increase in the rate of perfusion can boost the release of thromboxane whereas a reduction in blood flow can impair the ability of the venous wall to produce prostanoids (Onohara et al., 1993). In contrast, exercise training does not seem to affect the ability of the venous wall to release prostanoids (Brunkwall et al., 1989).

Vasoactive prostanoid production by the venous wall is altered by certain pathophysiological conditions. For example the ability of venous grafts to produce prostacyclin has been shown to be impaired and this seems to be connected with poor outcomes such as neointimal hyperplasia and thrombogenicity (Onohara et al., 1993). Additionally, an altered balance of prostacyclin and thromboxane production is linked to venous wall disease and is used as markers for venous occlusion thrombosis (Eldor et al., 1991). 


\subsubsection{Endothelial Relaxing Factor}

A variety of endothelial-derived relaxing and contracting factors such as nitric oxide (NO), prostacyclin, endothelium-derived hyperpolarizing factor, endothelin and thromboxane play a role in the endothelial-dependent control of vascular tone (Rongen, Smits \& Thien, 1992). The chemical structure of endothelium-derived relaxing factor, nitric oxide, activates cytoplasmic guanylate cyclase and thereby stimulates intracellular guanylate 3', 5'-cyclic monophosphate (cGMP) accumulation in vascular smooth muscle cells and platelets. cGMP functions as a second messenger to cause vascular muscle relaxation, inhibition of platelet aggregation and adhesion to vascular endothelial surfaces (Monocada, Palmer \& Higgs, 1991). Arterial and venous EDRF are closely similar although the pathway of action is different in arteries compared to veins (Buga et al., 1989; Yang et al., 1991). Endothelial-derived factors are determinants of the resting venous tone, which are dependent on an intact endothelium for a large number of vasodilator and vasoconstrictor substances. Additionally, the endothelial responses vary within the venous system and responses are generally smaller for veins compared to arteries, due in part, to the ability of the arteries to form more endothelium-derived relaxing factor (Barker, Anderson, Treasure \& Piper, 1994). In fact, the relaxation of veins to vasoactive agents such as acetylcholine, has an endothelium-dependent relaxant effect in human artery, but causes contraction on the veins. The differences in responsiveness of veins to vasoactive agents via EDRF may be due to 1) a more pronounced and direct smooth muscle effect of acetylcholine in veins; 2) the decreased ability of venous endothelial cells to release of EDRF; and 3) the depressed responsiveness of venous smooth muscle to the relaxing factor (Rubanyi \& Vanhoutte, 
1988). Furthermore, flow velocity and O2 tension may be another possible explanation since these factors are lower in the veins.

\subsection{Endothelial Constrictor Factors}

A number of constrictor factors are produced by the endothelium such as endothelin. Endothelin (ET-1) is a very potent vasoconstrictor peptide found throughout the vasculature. In fact, veins are more sensitive to this peptide than arteries compared to EDRF (Yanagisawa et al., 1988). Mechanisms of action of ET-1 suggest the mobilization of $\mathrm{CA} 2+$ from internal stores as well as ATP-sensitive potassium channels. Regulation of vascular tone is mediated by EDRF released from platelets andlor neutrophil granulocytes causing a basal vasodilator tone in veins. Also, NO derived from the central nervous system and from hepatic Kupffer cells, may also reach veins and thus influence their tone and responses. Diffusion between arterioles and accompanying venules is another possibility by which local vascular tone can be influenced (Falcone \& Bohlen, 1990).

In addition to ET-1, other agents elicit endothelium-dependent constriction. It has been shown that venous endothelial cells can metabolize arachidonic acid into a vasoconstrictor prostanoid. Also, the endothelial cells may control smooth muscle tone by indirect mechanisms such as the rubbing off of endothelial cells, which inhibited the release of NE by EDRF (Greenberg, Diecke, Peevy \& Tanaka, 1990). Although little is known about the role of EDRF in venous pathology, elevated levels of plasma ET have been implicated in several pathological conditions such as hypertension, myocardial infarction and cardiogenic shock (Leppaluoto \& Ruskoaho, 1992; Bax, Bos \& Saxena, 1993; Barber, Wang, Glovickzi \& Miller, 1997). 


\subsection{Histamine}

Two types of histamine receptors are found in venous tree, which include excitatory receptors $(\mathrm{H} 1)$ and inhibitory receptors $(\mathrm{H} 2)$. Both receptors have been associated with two distinct intracellular second messenger systems. The H1 receptors mediate many of their effects via inositol phospholipid hydrolysis; H1 also increases the release of calcium (Hill, 1991). The $\mathrm{H} 2$ receptors are coupled via a $\mathrm{G}$ regulatory protein to adenylate cyclase and stimulate cAMP formation; $\mathrm{H} 2$ receptors results in calcium depression. The sensitivity to histamine varies from one vein to another and it is thought that $\mathrm{H} 1$ receptors, which liberate EDRF, predominate over $\mathrm{H} 2$ receptors. Therefore, maximum tension development in some veins is substantially higher than others (Tsuru, Kohno, Iwata \& Shigel, 1987).

\subsection{Neurokinins}

Three different Neurokinins and three neurokinin receptors have been observed: substance P (SP), neurokinin A (NKA) and neurokinin B (NKB), which are most effective on the NK-1, NK-2 and NK-3 receptors. NK-1 is suggested to mediate peripheral vasodilation and exocrine secretion, NK-2 to stimulate bronchial muscles and to facilitate the release of catecholamines and NK-3 to promote the release of acetylcholine in peripheral organs (Regoli et al., 1989). The cGMP pathway through NO production in venous endothelial cells activates the mechanisms of action of neurokinins, such as substance P. All human veins studied responded with relaxation to neurokinins, however, on other veins dispensement of neurokinins resulted in contraction (Nantel et al., 1990). 


\subsection{Opiates}

Opiates, such as morphine, have a dilator effect on the venous system (Hakim, Grunstein, \& Michael, 1992). Mechanism of vasodilatory action exhibited in morphine may be attributable to sympathetic inhibition mediated by the presynaptic opiate receptors of the veins themselves or may also be mediated via the opiate receptors in the brain stem (Kobari, Gototh \& Fukuuchi, 1985).

\subsection{Serotonin}

The effect of serotonin (5-HT) on the cardiovascular system is complex, including bradycardia and tachycardia, hypotension and hypertension, and vasoconstriction and vasodilation. These actions are mediated by three main sets of receptors called 5-HT1, 5HT2 and 5-HT3 receptors. In most cases the majority of responses to veins to 5-HT receptors agonists is contraction, which is highly dependent on the presence of extracellular calcium (Bodelsson, Tornebrandt, Bertilsson \& Arneklo-Nobin, 1992). Serotonin has also been observed to induce vasodilation in certain veins. Three mechanisms of action that may attribute to the vasodilatory effects of 5-HT include inhibition of NE release from sympathetic nerve endings, direct vascular smooth muscle relaxation and release of EDRF (Gothert, Molderings, Fink \& Schlicker, 1991). Serotonin is also suggested to play a role in the pathogenesis of certain types of hypertension.

\subsection{Somatostatin}

Somatostatin has both constrictor and dilatory effects on venous smooth muscle that is not endothelium-dependent. Somatostatin may act on specific receptors, but the mechanism of venoconstriction by somatostatin and the interaction with vasoactive agents is still unclear. However, the most important role of somatostatins seems to be in 
the treatment of portal hypertension. Somatostatins are shown to increase portal venous outflow, reduce portal pressure and increase portal venous resistance (Rice, 1989).

\subsection{Neural Control of Veins}

The sympathetic nervous system controls the motor innervation of veins and is responsible for the contraction and relaxation of muscle layers in the tunica media that change vessel diameter. Afferent fibers also supply veins and are responsible for pain sensation. In great vessels near the heart, the afferent fibers react to changes in blood pressure and stimulate the autonomic system to respond these changes (Sansivero, 1998).

\subsection{Influence of Temperature on Venous Tone}

Alpha ${ }_{2}$-adrenoceptors, found in cutaneous arteries and veins, are responsible for the unique thermosensitivity, enabling constriction during local cooling to prevent heat loss (Flavahan, 1991). Superficial veins are temerature-dependent and are important in the regulation of environmental and skin temperature. However, these factors influence not only venous compliance, but also the responsiveness of the veins to the effects of constrictor agents. An increased responsiveness to constrictor agents such as 5-HT at low temperatures $\left(23^{\circ} \mathrm{C}\right)$ were observed in several studies (Aellig, 1994; Flavahan, 1991). Additionally, an application of ice to the forehead has shown to affect cutaneous circulation by causing venoconstriction of the forearms (Sumner, Zelis, Bennet \& Gascho, 1989).

\subsection{Effects of Age on Venous Tone}

Although declines in vasodilation and constriction have been observed in older individuals, the mechanisms for this decline are controversial. For example, evidence suggests that the decline in vasodilatory action is associated with a specific decrease in B- 
adrenoreceptor-mediated vascular relaxation (Pan, Hoffman, Pershe \& Blaschke, 1986). Other data suggests that the decreases in Beta-adrenoreceptor mediated smooth muscle relaxation with age was not due to a decrease in the number of Beta-adrenoreceptors, but to a decrease in cAMP accumulation induced by Beta-adrenoreceptor stimulation and probably another defect distal in the adenylcyclase pathway (Tsujimoto, Lee \& Hoffman, 1986). This blunted response was also seen in hypertensive patients. Studies where also carried out on the venoconstrictor responsiveness with age. Data have shown that a decrease in constrictor action is observed with age, although the mechanism responsible for this decline is not clear. Additionally, several studies have shown no differences in responsiveness to constrictor agents in old and young subjects (Pan et al., 1986). However, suggestions for the decline in venoconstriction in older individuals are associated with an age-related blunted response in post-synaptic $\mathrm{a}_{2}$-receptors or a down regulation of receptors due to a decrease in sympathetic tone (Supiano et al., 1991).

\subsection{Effects of Disease on Venous Function}

The role of the venous system in cardiovascular disease has been mentioned briefly throughout the paper. It appears that arteries as well as veins play an important role in many cardiovascular-related conditions. For example, hypertensive subjects exhibit a reduction in forearm venous distensibility compared to healthy counterparts. Possible mechanisms contributing to the decreases in distensibility include increases in venomotor tone as well as a reduction in forearm vasodilatory capacity (Walsh, Hyman \& Maronde, 1969). Additionally, Sudhir et al., 1990, found that veins from hypertensive patients exhibited an increased sensitivity to angiotensin II as well as reduced a-adrenoceptor responsiveness, linking the venous system to certain cardiovascular diseases. 
The venous function has also been related to other cardiovascular-related diseases such as $\mathrm{CHF}$, in which venous tone is shown to a direct relation with the severity of the disease (Ikenouchi et al., 1990; Sato et al., 1989). A reduction in venous compliance has also been observed in hand veins of patients immediately following a myocardial infarction. In varicose veins, functional, biochemical, and structural changes are seen, in which endothelin-1 is elevated but the contractile response is diminished (Thulesius, Ugaily-Thulesius, Gjores \& Neglen, 1988; Blochl-Daum et al., 1991; Lowell, Glovickzi $\&$ Miller, 1992). In fact, certain endothelin receptors have been characterized in varicose veins. Additionally, the diminished contractile response may be due to the downregulation of these receptors (Bax et al., 1993; Barber et al., 1997).

Certain peripheral vascular diseases such as PVD may be affected by venous function. Although underinvestigated, the venous system may play a more profound part than expected in conditions such as deep vein thrombosis (DVT) and symptoms associated with PVD. Schina et al., 1993, has shown that the incidence of DVT was closely linked with venous physiologic parameters: more specifically venous filling and ejection fraction. Moreover, the incidence of DVT increased significantly with agerelated changes in these parameters. 


\section{Chapter 3}

\section{Methods}

\subsection{Subjects}

Twenty-four males and females were recruited to participate in this study. Individuals with any acute medical condition andlor active infection, on drugs that affect vascular function, and $\backslash$ or tobacco users were excluded. All subjects were given informed consent and the Ethics Committee of Louisiana State University was approved the study. Prior to testing, all subjects were asked to avoid drugs that affect cardiovascular function and $\backslash$ or use tobacco. Subjects reported to the laboratory in the Kinesiology department at similar times for each testing session. A dietary recall was given to participants along with instructions regarding the testing procedures.

\subsection{Limitations}

This study was limited to apparently healthy cts 18-81 years of age from South Louisiana who were without any acute disease and who were not taking vasoactive drugs. Additionally, all subjects were students from the Department of Kinesiology or participants in the Exercise Training and Functional Ability in Older Adults Study conducted at Louisiana State University during 1998-2000.

\subsection{Experimental Measurements}

Each experimental session involved the measurement of forearm blood flow (FBF) at rest and following 5 minutes of forearm occlusion using an EC-5R plethysmography system, which consisted of arterial inflow (AI), venous capacitance (VC) and venous outflow (VO) for each session. 
Upon arrival to the laboratory, the subject's height, weight, hip to waist ratio, body composition, forearm circumference and length as well as grip strength were obtained. Thereafter, each subject was placed in a supine position for 20 minutes preceding the evaluation of FBF.

Prior to each measurement session, blood pressure cuffs were positioned around the midpoint of the participant's upper arm and wrist. Additionally, a mercury-insilastic strain gauge, $2-3 \mathrm{~cm}$ less than the forearm circumference, was placed around the forearm approximately $10 \mathrm{~cm}$ distal to the olecranon process (Cramer et al., 1983; Sinoway, Musch, Minotti \& Zelis, 1986). The forearm was extended and slightly supinated and supported by a Styrofoam block to be elevated above the heart level.

In order to obtain blood flow at rest, hand circulation was occluded for 1 minute by inflating the wrist cuff to $240 \mathrm{mmHg}$. Following 1 minute of wrist occlusion, the chart recorder was started at $5 \mathrm{~mm} / \mathrm{sec}$ and the calibration marker was activated followed by inflating the upper arm cuff to $50 \mathrm{mmHg}$ for 2 minutes and AI measurements were taken. This pressure was sufficient to occlude deep and superficial veins in the forearm to allow for venous filling (Cramer et al., 1983). After 2 minutes of venous occlusion the chart recorder was increased to $30 \mathrm{~mm} / \mathrm{sec}$ followed by deflating the upper arm cuff and measurements were obtained. This procedure was repeated once and separated by 5 minutes.

Total limb blood flow following ischemia was obtained by inflating the upper arm cuff to $240 \mathrm{mmHg}$ for 5 minutes (Sinoway et al., 1986). After 4 minutes of upper arm occlusion, the wrist cuff was inflated to $240 \mathrm{mmHg}$ for 1 minute, followed by deflating the upper arm cuff to $50 \mathrm{mmHg}$ in order to acquire AI measurements. The upper 
arm cuff pressure remained for 2 minutes and measurements following ischemia were obtained as described above.

Throughout the testing procedures, heart rate and blood pressure were obtained at the following time points: rest, during and immediately after occlusion. For the duration of the testing procedures, which lasted approximately 25 minutes, the subject remained in a supine position with minimal movement. Forearm venous outflow measurements were performed once, exactly one week apart.

\subsection{Data Analysis}

1. Arterial inflow rates were calculated by measuring the initial slope. This was determined by drawing a line on the recorded output tangent to the first few pulses following cuff inflation. Flow rate was expressed as a volume change per unit time such as ml's of blood flow/ 100 ml's of tissue/ minute.

2. Venous capacitance was calculated by measuring the distance in $\mathrm{mm}$ from the baseline to the maximum height of the inflow curve and dividing this distance by the height of the calibration mark (CAL).

3. Forearm venous outflow was calculated for each session by measuring the distance in $\mathrm{mm}$ from the baseline to the maximum height of the (CAL).

Subsequently, VO was calculated at $0.5\left(\mathrm{VO}_{.5}\right)$ and $2\left(\mathrm{VO}_{2}\right)$ seconds after cuff deflation, and the respective excursions of the curve from the baseline at both time periods were measured and divided by CAL. The resultant number, a volume, was converted into a rate of flow in $\mathrm{ml}$ per min per $100 \mathrm{ml}$ of tissue by introducing a time normalizing factor using the following formulas (Cramer et al., 1983): 


$$
\begin{aligned}
& \mathrm{VO}_{.5}=\text { excursion from the baseline } \backslash \mathrm{CAL} * 120 \\
& \mathrm{VO}_{2}=\text { excursion from the baseline } \backslash \mathrm{CAL} * 30
\end{aligned}
$$

The outflow interval between 0.5 and 2 seconds $\left(\mathrm{VO}_{.5-2}\right)$ was calculated by the equation:

$$
\mathrm{VO}_{.5-2}=(4 \backslash 3) \mathrm{VO}_{2}-(1 \backslash 3) \mathrm{VO}_{.5}
$$

4. The area under the curve (AUC) was also selected as a potentially more meaningful measure of blood flow. The area under the curves for VO between the $0.5 \mathrm{sec}$ and $2.0 \mathrm{sec}$ time intervals in a subset of the study sample were examined for an association with the accepted method of estimation by slope calculation.

\subsection{Statistical Analysis}

Statistical analysis was performed using the SPSS for Windows statistical package (version 10.0). Descriptive data was presented, as mean $\pm \mathrm{sd}$. Intraclass correlation coefficients were derived from repeated measures Analysis of Variance for the purpose of examining the test re-test reliability of FBF, blood pressure, and heart rate during rest and following ischemia in visits I and II. Alpha was set a-prior at 0.05. A Pearson Product Moment Correlation was used to compare FBF with anthropometrical measures, heart rate, age and gender for each condition. 


\section{Chapter 4}

\section{Results}

\subsection{Subjects}

Table 1 shows the characteristics of male and female subjects. Twenty-four apparently healthy subjects ( $\mathrm{N}=14$ females, $\mathrm{N}=10$ males) were recruited to participate in this study. All of the original 24 subjects completed the study. Subjects were required to successfully complete both trials to be included in the final results. Participants ranged in age from $18-81$ yrs. There was a wide-inter-individual height and weight range among all subjects tested with a maximum height recorded as 75 inches and minimum height was recorded as 61 inches. Weight ranged from a maximum of $113.6 \mathrm{~kg}$ to a minimum weight of $50.4 \mathrm{~kg}$. Body Mass Index (BMI) ranged from a maximum value of 35.85 to a minimum value of 19.34 . Body fat percentage ranged from a maximum value of $44 \%$ to a minimum value of $12 \%$. Arm length and circumference extended from maximum values of 29 and $31.5 \mathrm{~cm}$ to minimum values of 22 and $21 \mathrm{~cm}$, respectively. The average of three maximal voluntary contractions were taken with a handgrip dynamometer and ranged with maximum value of $66.3 \mathrm{~kg}$ to a minimum value of $20.6 \mathrm{~kg}$. Blood pressure and heart rate were recorded at rest and ranged from highest to lowest value of 170 to 94 mmHg systolic, 97 to $35 \mathrm{mmHg}$ diastolic and 85 to 45 beats per minute for heart rate.

\subsection{Within-Day Flow at Rest}

FBF for within-day measures at rest are reported in table 2. Values for all FBF indices were in expected ranges as reported by others. Intraclass Correlation Coefficient (ICC) for FBF are also reported in table 2, which show strong reliability for all blood flow indices, with the AI having the lowest ICC. 
Table 1. Subject Demographics

\begin{tabular}{llll}
\hline & Minimum & Maximum & Mean $\pm \mathrm{SD}$ \\
\hline Age & 19 & 81 & $39.9 \pm 18$ \\
Height (in) & 60 & 75 & $66.9 \pm 3.84$ \\
Weight (kg) & 49.5 & 113.6 & $72.6 \pm 16.5$ \\
BMI & 19.3 & 35.8 & $24.5 \pm 3.89$ \\
Body Fat & 12 & 44 & $24.1 \pm 6.62$ \\
Arm Lg (mm) & 22 & 29 & $24.8 \pm 1.91$ \\
Arm Circ (mm) & 21 & 31.5 & $26.1 \pm 3.35$ \\
MVC & 20.6 & 66.3 & $38.2 \pm 12.1$ \\
SBP & 94 & 170 & $119.7 \pm 20.3$ \\
DBP & 35 & 97 & $60.2 \pm 16.7$ \\
HR & 45 & 85 & $63 \pm 11.1$ \\
\hline Arm Lg = arm length, Arm Circ = arm circumference, BMI $=$ body \\
mass index, MVC = maximal voluntary contraction, SBP $=$ systolic \\
blood pressure, DBP= diastolic blood pressure, HR= heart rate.
\end{tabular}

Table 2. Within-Day 1 Resting Blood Flow Indices

\begin{tabular}{|c|c|c|c|c|}
\hline Indices & Minimum & Maximum & Mean $\pm \mathrm{SD}$ & $\mathrm{ICC}$ \\
\hline $\mathrm{AI}_{\mathrm{A}}$ & 1.86 & 7.95 & $4.45 \pm 1.63$ & .87 \\
\hline $\mathrm{AI}_{\mathrm{B}}$ & 1.92 & 7.93 & $4.28 \pm 1.71$ & \\
\hline $\mathrm{VC}_{\mathrm{A}}$ & 1.50 & 3.60 & $2.78 \pm 0.46$ & .93 \\
\hline $\mathrm{VC}_{\mathrm{B}}$ & 1.40 & 3.40 & $2.73 \pm 0.46$ & \\
\hline $\mathrm{VO}_{.5 \mathrm{sec} A}$ & 55.2 & 140.4 & $99.5 \pm 26.4$ & .94 \\
\hline $\mathrm{VO}_{.5 \mathrm{secB}}$ & 48.0 & 140.4 & $94.4 \pm 27.3$ & \\
\hline $\mathrm{VO}_{2 \sec \mathrm{A}}$ & 24.0 & 67.8 & $48.2 \pm 12.2$ & .96 \\
\hline $\mathrm{VO}_{2 \mathrm{secB}}$ & 22.0 & 64.5 & $46.1 \pm 11.6$ & \\
\hline $\mathrm{VO}_{.5-2 \mathrm{~A}}$ & 13.6 & 48.0 & $31.1 \pm 9.51$ & .97 \\
\hline $\mathrm{VO}_{.5-2 \mathrm{~B}}$ & 12.6 & 49.6 & $29.9 \pm 8.48$ & \\
\hline
\end{tabular}

\subsection{Between-Day Flow at Rest}

FBF for between-day measures at rest are reported in table 3. All blood flow values were similar to those reported for within-day measures in table 2. However ICC's for FBF between-days showed weaker reliability, with the least reliable measure reported for venous outflow at the time interval between .5-2 seconds. 
Table 3. Between-Day Resting Blood Flow Indices

\begin{tabular}{lllll}
\hline Indices & Minimum & Maximum & Mean \pm SD & ICC \\
\hline $\mathrm{AI}_{\mathrm{I}}$ & 2.00 & 8.00 & $4.01 \pm 1.50$ & .51 \\
$\mathrm{AI}_{\text {II }}$ & 2.00 & 7.75 & $3.69 \pm 1.36$ & \\
$\mathrm{VC}_{\mathrm{I}}$ & 2.00 & 4.00 & $2.93 \pm 0.47$ & .62 \\
$\mathrm{VC}_{\mathrm{II}}$ & 1.90 & 4.00 & $2.82 \pm 0.57$ & \\
$\mathrm{VO} .5$ secI & 36.0 & 146.4 & $96.8 \pm 27.6$ & .70 \\
$\mathrm{VO} .5$ secII & 48.0 & 140.4 & $94.4 \pm 27.3$ & \\
$\mathrm{VO}_{2 \text { secI }}$ & 39.6 & 134.0 & $91.2 \pm 26.4$ & .51 \\
$\mathrm{VO}_{2 \text { secII }}$ & 25.2 & 69.0 & $45.3 \pm 12.1$ & \\
$\mathrm{VO}_{.5-2 \mathrm{I}}$ & 16.4 & 42.4 & $30.1 \pm 7.75$ & .43 \\
$\mathrm{VO}_{5-\text {-2II }}$ & 18.0 & 54.8 & $30.1 \pm 9.23$ & \\
\hline
\end{tabular}

Other acronyms are reported in Table 2.

\subsection{Between-Day Flow Following Occlusion}

Between-day measures for FBF following occlusion are reported in table 4. All blood flow values reported in table 4 were in expected range. Similarly, ICC's reported for AI were as anticipated with reliability being somewhat higher than those reported for between-day measures at rest.

Table 4. Between-Day Ischemic Blood Flow Indices

\begin{tabular}{lllll}
\hline Indices & Minimum & Maximum & Mean \pm SD & ICC \\
\hline $\mathrm{AI}_{\mathrm{I}}$ & 20.0 & 35.8 & $26.6 \pm 4.47$ & .81 \\
$\mathrm{AI}_{\text {II }}$ & 20.0 & 45.9 & $26.3 \pm 6.11$ & \\
$\mathrm{VC}_{\mathrm{I}}$ & 1.60 & 3.40 & $2.56 \pm 0.45$ & .56 \\
$\mathrm{VC}_{\text {II }}$ & 1.80 & 3.50 & $2.73 \pm 0.43$ & \\
$\mathrm{VO} .5$ secI & 60.0 & 146.4 & $98.6 \pm 26.7$ & .70 \\
$\mathrm{VO}_{.5 \text { secII }}$ & 39.6 & 132.0 & $97.1 \pm 25.6$ & \\
$\mathrm{VO}_{2 \text { secI }}$ & 26.7 & 72.6 & $49.3 \pm 12.8$ & .64 \\
$\mathrm{VO}_{2 \text { secII }}$ & 27.0 & 70.2 & $49.4 \pm 11.4$ & \\
$\mathrm{VO}_{.5-2 \mathrm{I}}$ & 12.0 & 50.8 & $32.8 \pm 10.1$ & .63 \\
$\mathrm{VO}_{5 \text {-2II }}$ & 18.0 & 51.6 & $33.4 \pm 8.45$ & \\
\hline
\end{tabular}

Other acronyms are reported in Table 2.

\subsection{Correlation Among Variables}

An analysis of co-variance was performed to determine the correlation between FBF for Day I and II under both conditions with anthropometrical measures, age, gender, and HR among the 24 subjects tested. AI was the only measure to correlate strongly with VC for both days with day II showing a weaker association $(\mathrm{r}=.500, \mathrm{p}<.09 ; \mathrm{r}=.329, \mathrm{p}<$ .11). However, AI showed a somewhat lesser correlation when compared to $\mathrm{VO}_{2}$ and 
$\mathrm{VO}_{.5-2}$ for day II $(\mathrm{r}=.394, \mathrm{p}<.05 ; \mathrm{r}=.399, \mathrm{p}<.05)$, respectively. In addition, venous measures were strongly correlated with various venous indicators. For example, VC demonstrated a strong association for the following venous markers for day I: $\mathrm{VO}_{.5}, \mathrm{VO}_{2}$ and $\mathrm{VO}_{.5-2}(\mathrm{r}=.538, \mathrm{p}<.005 ; \mathrm{r}=.753, \mathrm{p}<.0001 ; \mathrm{r}=.789, \mathrm{p}<.0001)$, respectively. As expected, $\mathrm{VO}_{.5}$ was associated with $\mathrm{VO}_{2}$ and $\mathrm{VO}_{.5-2}$ for day $\mathrm{I}(\mathrm{r}=.877, \mathrm{p}<.0001 ; \mathrm{r}=.431$, $\mathrm{p}<.03)$ as well as $\mathrm{VO}_{.5-2}$ for Day II $(\mathrm{r}=.574, \mathrm{p}<.002) . \mathrm{VO}_{2}$ was also strongly correlated with $\mathrm{VO}_{.5-2}$ for day $\mathrm{I}(\mathrm{r}=.896, \mathrm{P}<.0001)$. Additionally, $\mathrm{VC}$ was correlated with the following venous markers: $\mathrm{VO}_{.5}, \mathrm{VO}_{2}$ and $\mathrm{VO}_{.5-2}(\mathrm{r}=.509, \mathrm{p}<.01 ; \mathrm{r}=.651, \mathrm{p}<.0004 ; \mathrm{r}$ $=.702, \mathrm{p}<.0001)$ for day II, respectively. Venous marker $\mathrm{VO}_{.5}$ was also associated with $\mathrm{VO}_{2}(\mathrm{r}=.931, \mathrm{p}<.0001)$ as well as $\mathrm{VO}_{.5-2}(\mathrm{r}=.682, \mathrm{p}<.0001)$ for day II. Lastly, a significant association was found between $\mathrm{VO}_{2}$ and $\mathrm{VO}_{.5-2}$ for day II $(\mathrm{r}=.902, \mathrm{p}<.0001)$. Various venous markers demonstrated a relationship with heart rate. Heart rate was inversely associated with all venous indices for day II only $(\mathrm{r}=-.417, \mathrm{p}<.04 ; \mathrm{r}=-.501$, $\mathrm{p}<.01 ; \mathrm{r}=-.485, \mathrm{p}<.01 ; \mathrm{r}=-.378, \mathrm{p}<.0001)$.

Certain anthropometrical measures were also found to be inversely associated with FBF. Height was associated with VC at both days $(\mathrm{r}=.352, \mathrm{p}<.09 ; \mathrm{r}=.227, \mathrm{p}<$ .19). An inverse association was also seen for between height and $\mathrm{VO}_{.5}$ and $\mathrm{VO}_{2}$ for day II only $(\mathrm{r}=-.273, \mathrm{p}<.19 ; \mathrm{r}=-.377, \mathrm{p}<.06)$. AI was the only measure found to have an inverse association with body fat $(\mathrm{r}=-.359, \mathrm{p}<.08)$. Markers $\mathrm{VO}_{.5}$ and $\mathrm{VO}_{2}$ demonstrated an inverse relationship with arm length for day II only $(r=-.430, p<.03 ; r$ $=-.344, \mathrm{p}<.09)$, respectively. AI demonstrated an inverse association with gender for day I only $(\mathrm{r}=-.345, \mathrm{p}<.09)$. Similarly, $\mathrm{VC}$ demonstrated a strong, inverse relationship with 
gender for day II only $(\mathrm{r}=-.513, \mathrm{p}<.009)$. Finally, venous marker $\mathrm{VO}_{.5-2}$ was inversely associated with age for day I only $(\mathrm{r}=-.340, \mathrm{p}<.10)$.

\subsection{Multiple Regression}

A stepwise regression was performed between venous measures and subject characteristics. Arm length, hence vessel length, was found to have important predictive value in VO markers measured at the time interval of .5 seconds $(F=4.979, \mathrm{p}<.03)$. Similarly, gender was found to have important predictive value for $\mathrm{VC}(\mathrm{F}=7.862, \mathrm{p}<.01)$.

\subsection{Area Under the Curve}

Quantification of forearm blood flow using venous plethysmography essentially is based on a derived slope of the change in diameter of the forearm. While this technique has gained wide acceptance, there is some error that is associated with this technique largely due to problems associated with selecting the points across which the slope is determined. Therefore, there has been some interest in selecting the area under the curve of the change in diameter during a standardized time period as a potentially more meaningful measure of blood flow. Therefore, we examined the area under the curves for venous outflow between the $0.5 \mathrm{sec}$ and $2.0 \mathrm{sec}$ time intervals in a subset of the study sample and examined these areas for an association with the accepted method of estimation by slope calculation. Thus, we were simply assessing the construct validity of the measure.

The method used by Cramer et al., 1983, to assess blood flow was compared with AUC technique. Figure $4.1 \& 4.2$ revealed a strong correlation between both methods for resting $\mathrm{VO}$ at the time interval $.5-2 \mathrm{sec}$ for day $\mathrm{I}\left(\mathrm{r}=.86, \mathrm{p}<.01\right.$ for $\mathrm{VO}_{\mathrm{A}} ; \mathrm{r}=.85, \mathrm{p}<.01$ for $\left.\mathrm{VO}_{\mathrm{B}}\right)$. 


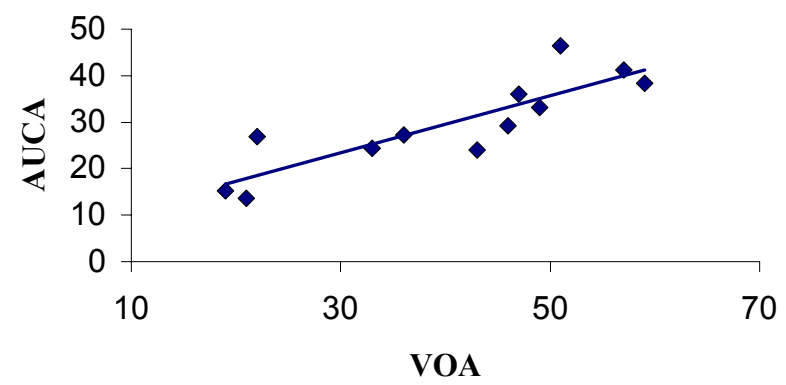

Figure 4.1 Cramer's Method VS AUC Day I A

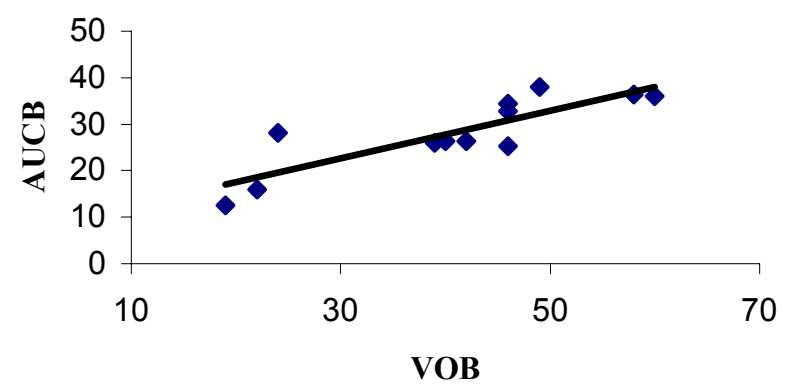

Figure 4.2 Cramer's Method VS AUC DAY I B

Figure 4.3 shows a comparison of both measurement techniques for $\mathrm{VO}$ following ischemia at the time $.5-2 \mathrm{sec}$. Similarly Cramer's method was strongly correlated with AUC, showing a correlation coefficient of $r=.90(p<.01)$. Additionally, the short-term reliability of the AUC technique was assessed during rest, revealing an ICC of $r=.90(p<$ $.71)$. 


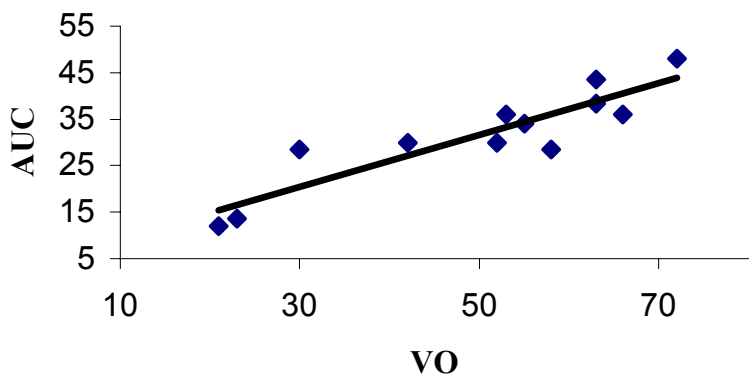

Figure 4.3 Cramer's Method VS AUC Following Ischemia Day I 


\section{Chapter 5}

\section{Discussion}

The purpose of this study was to evaluate the reproducibility, using venous occlusion plethysmography, of forearm venous outflow during rest and following ischemia. A secondary purpose was to compare the association of FBF with subject characteristics such as anthropometrical measures, age, gender, and HR among the 24 subjects tested. A stepwise regression was also performed to determine predictive value between venous measures and subject characteristics. Finally, the construct validity of area under the curve was compared to the accepted method used by Cramer to determine venous outflow.

All data for the variables of interest were in expected ranges. Arterial inflow measures at rest ranged from $1-8 \mathrm{ml} / 100 \mathrm{ml}$ of tissue/minute. These measures were similar to that reported by Altenkirch et al., 1989, 1990. Measures obtained for AI following ischemia coincided with those found by Sinoway et al., 1986, extending from $20-46 \mathrm{ml} / 100 \mathrm{ml}$ of tissue/minute. Additionally, all venous measures during both conditions were comparable to those established by Cramer et al., 1983, with VC ranging from 1-4 and $\mathrm{VO}_{.5-2}$ ranging from $12-54 \mathrm{ml} / 100 \mathrm{ml}$ of tissue/ minute. Therefore, data appear to be reasonable, and in line with the range of expected values seen in other studies.

Within-day reliability for FBF measures at rest is reported in figures 5.1, 5.2 and 5.3. Our data revealed that the SGP was highly reliable when measuring FBF withindays, giving an r- value of $.87, .93$, and .97 for $\mathrm{AI}, \mathrm{VC}$, and $\mathrm{VO} .5-2$, respectively. In fact our data were in line with others such as Sinoway et al., 1986, who reported a short-term 
reliability coefficient for FBF measures such as hyperemic AI as $r=.84$. Altenkirch et al., 1989, also found SGP to have good short-term reliability. Interestingly, Altenkirch, as well as our study, observed higher degree of variation in AI measures, which subsequently revealed a lower reliability coefficient than other FBF measures $(r=.87)$.

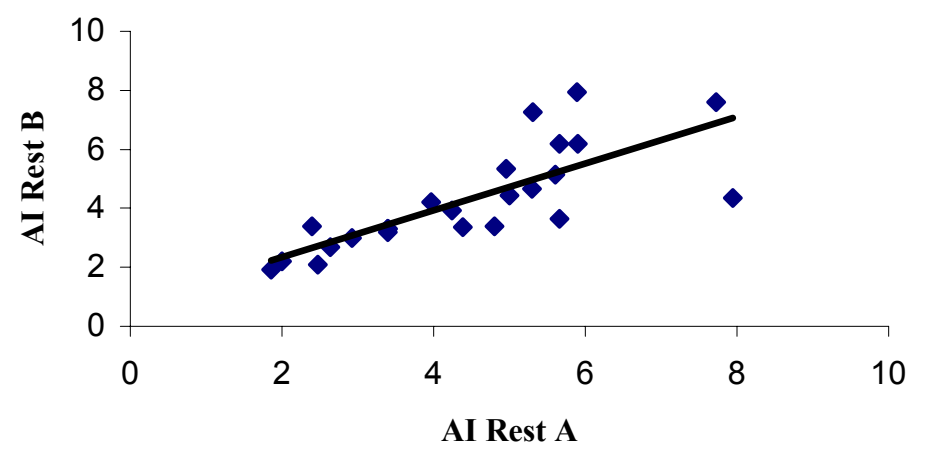

Figure 5.1 Within-Day Reliability for AI Rest

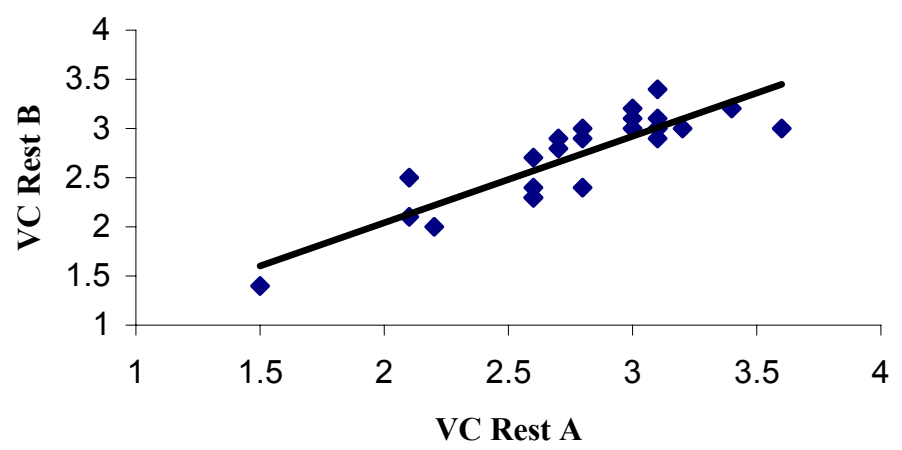

Figure 5.2 Within-Day Reliability for VC Rest 


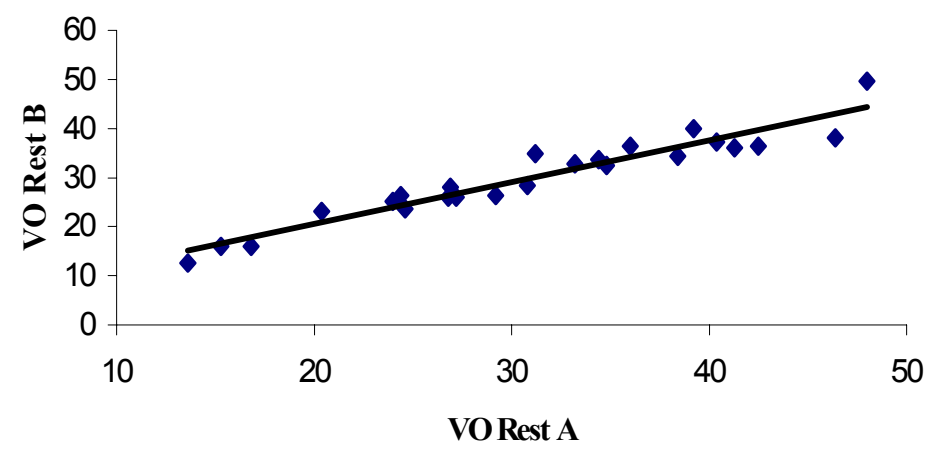

Figure 5.3 Within-Day Reliability for VO Rest

On the other hand, long-term measurement of FBF at rest was less reliable as shown in figures 5.4, 5.5 and 5.6. Results obtained in our study demonstrated long-term reliability for all FBF to be unacceptable, with reliability ranging from $.51, .62$, and .43 for AI, VC, and $\mathrm{VO}_{.5-2}$ at rest. This trend is also consistent with Altenkirch et al., 1990, as well as Neubauer, et al., 2000, who found weak long-term reliability for resting measures taken at one-week intervals, with a reliability coefficient of $r=.65, r=.52$ and $r$ $=.68$, reported for $\mathrm{AI}, \mathrm{VC}$ and $\mathrm{VO}$.

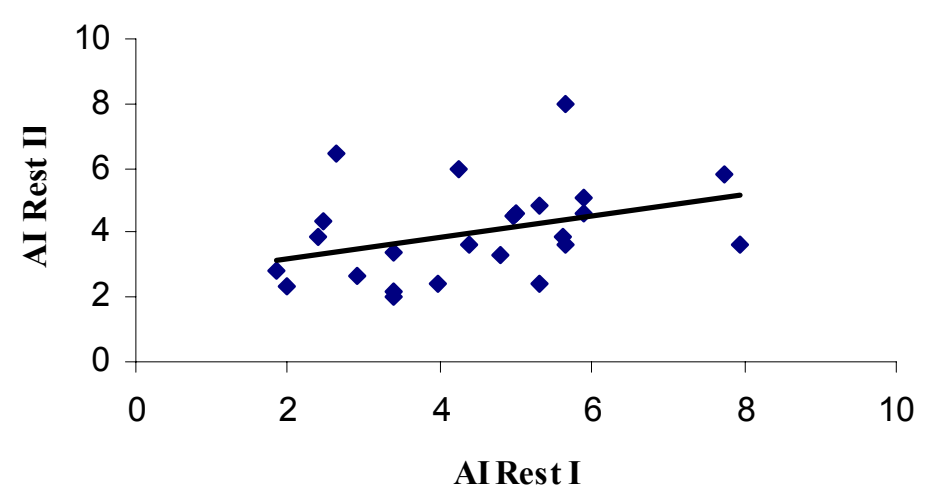

Figure 5.4 Between-Day Reliability for AI Rest 


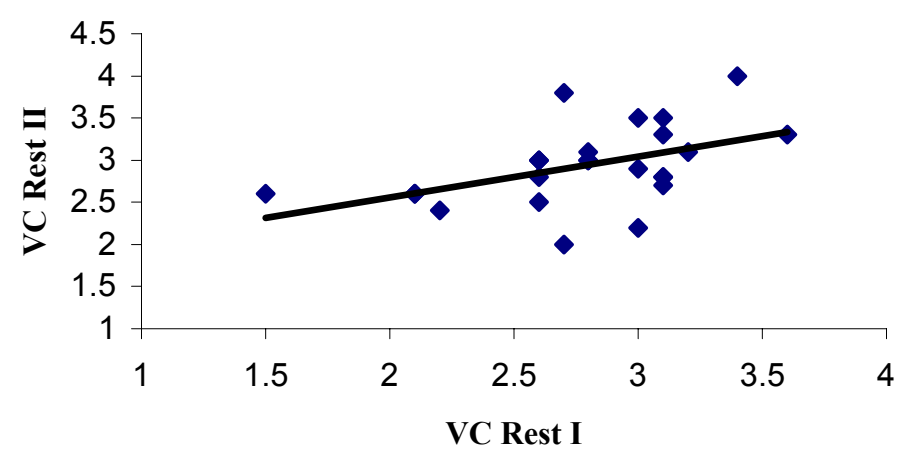

Figure 5.5 Between-Day Reliability for VC Rest

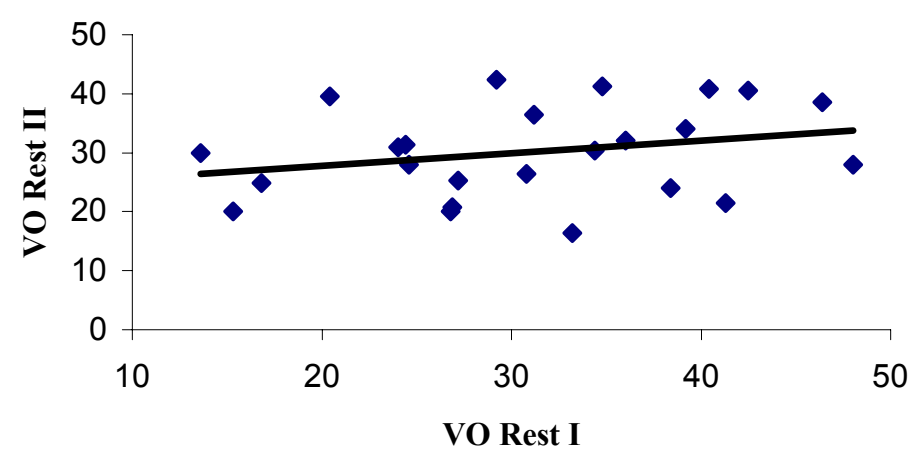

Figure 5.6 Between-Day Reliability for VO Rest

Additionally, all hyperemic FBF measures taken between-days are reported in figures 5.7, 5.8 and 5.9, revealing an r-value of .81, .56, and .63 for AI, VC, and VO .5-2, with only AI having acceptable reliability. Altenkirch et al., 1990, found hyperemic measures taken between-days to be highly variable. Neubauer et al., 2000, also reported a higher coefficient of reliability for AI following ischemia as $\mathrm{r}=.76$. 


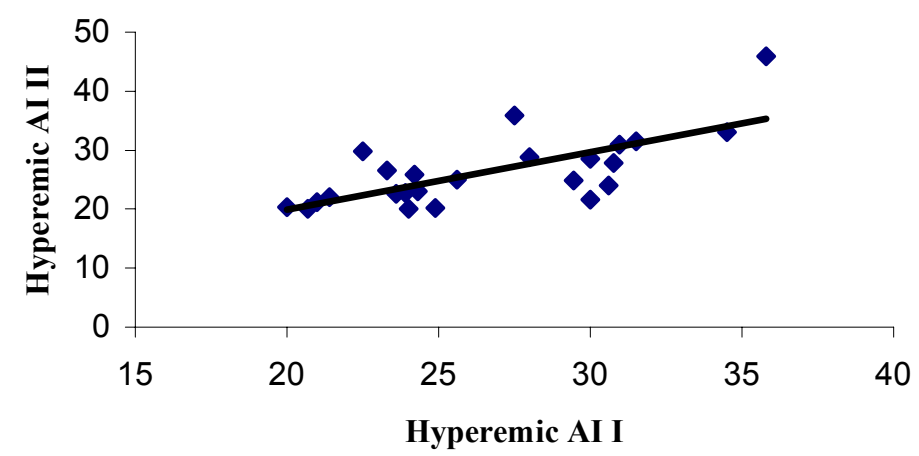

Figure 5.7 Between-Day Reliability for Hyperemic AI

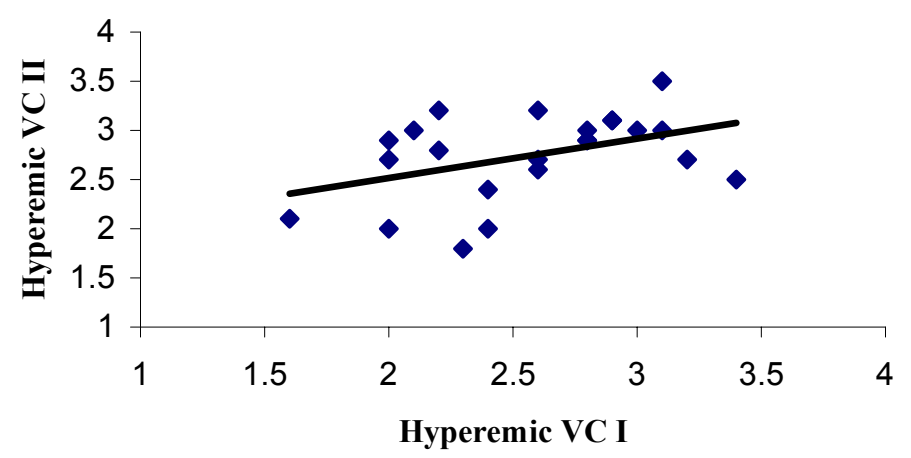

Figure 5.8 Between-Day Reliability for Hyperemic VC

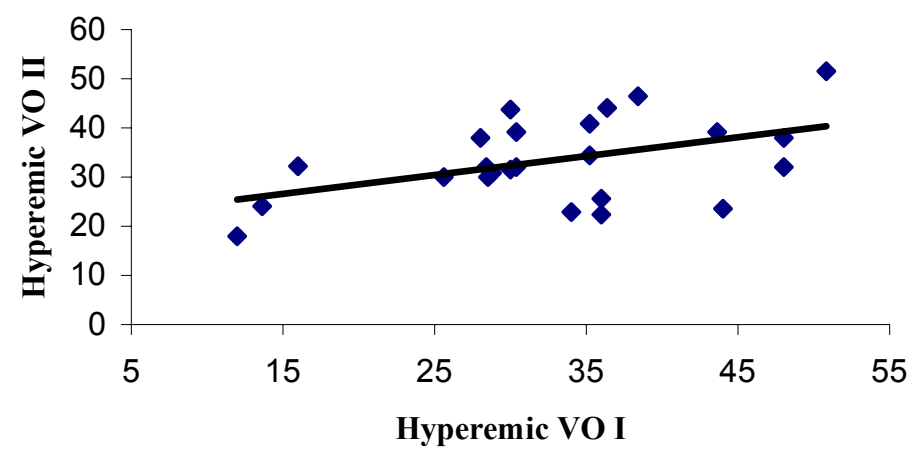

Figure 5.9 Between-Day Reliability for Hyperemic VO 
Altenkirch has suggested that the poor reliability seen in long-term measures may be due to biological factors such as electrolytes, hormones, and temperature that may contribute to the variability in these measures. Furthermore, the arterial side of the circulation seems to have larger degree of day-to-day variability at rest than the venous side, although it is unclear why. One possible explanation could be that the arterial side is more vasoactive, which would explain the differences in these measures. In contrast, reliability seen for hyperemic AI measures may be due, in part, to a build up of ischemic metabolites, which may provide a stimulus that is strong enough to override any factors that may contribute to the variation in these measures. This may contribute to the day-today stability of hyperemic AI.

Other factors, which may not be physiological, may explain some variation in the measurements. For example, Fehling, Arciero, MacPherson \& Smith, 1999, found that variations in measures be also be due discrepancies in the acquisition of the waveform, reinforcing the necessity of following a strict set of testing guidelines when obtaining FBF measures. Altenkirch also suggests that the forearm itself may be poorly suited for intervention studies in cardiovascular control, since it is composed mostly of skin, which may make physiological factors more influential on FBF.

Although hyperemic AI was found to have acceptable reliability, resting FBF measures may be more beneficial when studying disease. SGP may be more appropriate for serial measures taken within-days and may be problematic in longitudinal studies, due to the low degree of long-term reliability.

Pearson correlations were done to determine the relationship of FBF with HR, age, gender and anthropometrical measures. Heart rate was found to be inversely 
associated with all $\mathrm{VO}$ indices. Although it is unclear, this association may be explained by the cardiopulmonary baroreceptor. This baroreceptor, located in the left ventricle, right atrium and large veins, is sensitive to changes in arterial pressure and may explain why those with lower VO indices also had higher heart rates.

Certain subject characteristics were also found to be significantly associated with venous measures. Height and arm length was found to be inversely associated with venous measures. This, according to Pousouille's Law, could reflect the influence a vessel has on resistance to flow. This resistance to flow may be particular importance in a low-pressure circuit such as the venous system, since those with greater height and arm length had lower venous measures.

As expected, VO was also inversely associated with age. This finding is consistent in other reports describing the relationship between VO and age. Studies relating the association between aging and endothelial dysfunction such as Gerhard, Roddy, Shelly and Creager, 1995, as well as Andrawis, Jones and Abernathy, 2000, have found an inverse association between age and vascular dysfunction. It was hypothesized in these studies that the age-related differences in blood flow was due to a decline in the release or activity of endothelium-derived nitric oxide. This loss of vasodilatory function and hence blood flow, is thought to contribute to the increased risk of atherosclerosis and thrombosis with adult aging (DeSouza et al., 2000).

A stepwise regression indicated that vessel length was the strongest predictor for venous measures. The inclusion of other measures added less to the prediction equation. This is interesting when one considers the sudden death incidence among athletes being particularly high in basketball players. 
We examined the area under the curves for venous outflow between the $0.5 \mathrm{sec}$ and $2.0 \mathrm{sec}$ time intervals in a subset of the study sample to assess the construct validity of the measure. Cramer's method used to assess VO was compared to AUC technique and was found to be highly associated with VO at all time intervals. Additionally, the AUC technique was found to be highly reliable, which may make this technique a potentially more meaningful measure of VO.

Although the venous occlusion plethysmography technique was found to have good short-term reliability, future studies should focus on the improvement of long-term reliability. Studies should also focus on venous indices as being a more meaningful measure of disease. Additionally, AUC may have potential importance as an assessment tool for VO, and therefore more attention should be given to the development this technique. 


\section{References}

Aburto, T. K., Lajoie, C., \& Morgan, K. G. (1993). Mechanism of signal transduction during alpha 2-adrenergic receptor-mediated contraction of vascular smoothe muscle. Circulation Research, 72, 778-85.

Aellig, H. W. (1994). Clinical pharmacology, physiology and pathophysiology of superficial veins. British Journal of Clinical Pharmacology, 38, 181-196

Allen, J. C., Kahn, A. M., \& Navran, S. S. (1986). $\mathrm{Na}^{+}-\mathrm{K}^{+}-\mathrm{ATPase}$ in vascular smooth muscle. American Journal of Physiology, 250, C536-40.

Altenkirch, H. U., Fransson, L. \& Koch, G. (1989). Assessment of arterial and venous circulation in upper and lower extremities by venous occlusion strain gauge plethysmography. Normal values and reproducibility. VASA, 18, 140-5.

Altenkirch, H. U., Koch, G. \& Koralewski, H.E. (1990). Variability and reproducibility of arterial and venous circulation parameters in the forearm and calf measures at one-week intervals. VASA, 19, 21-5.

Altura, B. M., \& Altura, B. T. (1984). Interactions of $\mathrm{Mg}$ and K on blood vessels-Aspects in view of hypertension. Magnesium, 3, 175-194.

Ando, S., Imaizumi, T., Harada, S., Hirooka, Y., \& Takeshita, A. (1992). Atrial natriuretic peptide increases human capillary filtration and venous distensibility. Journal of Hypertension, 10, 451-7.

Andrawis, N., Jones, D.S. \& Abernathy, D.R. (2000). Aging is associated with endothelial dysfunction in the human forearm vasculature. Journal of American Geriatric Society, 48, 193-198.

Archie, J. P., \& Green, J. J. (1990). Saphenous vein rupture pressure, rupture stress, and carotid endarterectomy vein patch reconstruction. Surgery, 107, 389-396.

Arner, M., \& Hogestatt, E. D. (1991). Endothelium-dependent relaxation and effects of prostacyclin, endothelium, and platelet-activating factor in human hand veins and arteries. Acta Physiologica Scandinavia, 142, 165-172.

Barber, D. A., Wang, X., Glovickzi, P. \& Miller, V. M. (1997). Characterization of endothelin receptors in human varicose veins. Journal of Vascular Surgery, 26, 61-9.

Barker, J. E., Anderson, J., Treasure, T. \& Piper, P. J. (1994). Influence of endothelium and surgical preparation on responses of human saphenous vein and 
internal thoracic artery to angiotensin II. British Journal of Clinical Pharmacology, $\underline{38,57-62 .}$

Baron, A., Loirand, G., Pacaud, P., Mironneau, C., \& Mironneau, J. (1993). Dual effect of thrombin on voltage-dependent $\mathrm{Ca}^{2+}$-activated $\mathrm{Cl}^{-}$current in rat vascular smooth muscle cells. Circulation Research, 72, 1317-25.

Bax, W. A., Bos, E. \& Saxena, R. P. (1993). Heterogeneity of endothelin/sarafotoxin receptors mediating contraction of the human isolated saphenous vein. European Journal of Pharmacology, 239, 267-8.

Beech, D. J., \& Bolton, T. B. (1989). Two components of potassium current activated by depolarization of single smoothe muscle cells from the rabbit portal vein. Journal Physiology London, 418, 293-9.

Bevan, J. A., \& Joyce, E. H. (1990). Saline infusion into lumen of resistance artery and small veins causes contraction. American Journal of Physiology, 259, H2328.

Bevan, J. A. \& Siegel, G. (1991). Blood vessel matrix flow sensor. Evidence and speculation. Blood Vessels, 28, 552-556.

Bevan, J. A., \& Joyce, E. H. (1992). Comparable sensitivity of flow contraction and relaxation to Na reduction may reflect flow-sensor characteristics. American Journal of Physiology, 263, H182-87.

Bevan, J. A., \& Joyce, E. H. (1993). Calcium dependence of flow-induced dilation. Cooperative interaction with sodium. Hypertension Dallas, 21, 16-21.

Bienvenu, K., \& Granger, D. N. (1992). Molecular determinants of shear ratedependent leukocyte adhesion in postcapillary venules. American Journal of Physiology, 264, H1504-8.

Blochl-Daum, B., Schuller-Petrovic, S., Woltz, M., Korn, A., Bohler, K. \& Eichler, H. (1991). Primary defect in alpha-adrenergic responsiveness in patients with varicose veins. Pharmacodynamics and Drug Action, 49, 49-52.

Bodelsson, M., Tornebrandt, K. Bertilsson, I. L., \& Arneklo-Nobin, B. (1992). Heterogeneity of contractile 5-HT receptors in human hand veins. European Journal of Pharmacology, 219, 455-60.

Bretag, H. A. (1987). Muscle chloride channels. Physiological Reviews, 67, 618-724. 
Brock, T. A., Brugnara, C., Canessa, M., \& Gimbrone, M. A. (1986). Bradykinin and vasopressin stimulate $\mathrm{Na}^{2+}-\mathrm{K}^{+}-\mathrm{Cl}$ - cotransport in cultured endothelial cells. American Journal of Physiology, 250, C888-95.

Brunkwall, J. S., Stanley, J. C., Kresowik, T. F., Graham, L. M., Burkel, W. E. $\&$ Berqvist, D. (1989). Prostanoid release from ex vivo perfused canine arteries and veins: Effects of prolonged perfusion, intermittent perfusion, as well as exposure to exogenous arachidonic acid, thrombin and bradykinin. Thrombosis Haemostasis, 62 , 1034-39.

Buga, G. M., Gold, M. E., Wood, K. S., Chaudhuri, G., \& Ignarro, L. J. (1989). Endothelium-derived nitric oxide relaxes nonvascular smooth muscle. European Journal of Physiology, 161, 61-72.

Chiavarelli, M., Fabi, F., Stati, T., Chiavarelli, R., \& Del Basso, P. (1992). Effects of cardioplegic solution and their components on human saphenous vein contractility. Annals in Thoracic Surgery, 53, 455-59.

Corbally, M. T., \& Brennan, M. F. (1990). Non-invasive measurement of regional blood flow in man. American Journal of Surgery, 2, 313-21.

Cramer, M., Langlois, Y., Beach, K., Martin, D., and Strandness, D. E., Jr. (1983). Standardization of venous outflow measurements by strain gauge plethysmography in normal subjects. Bruit VII, 33-39.

Dachman, D., Ford, G. A., Blaschke, T. F., \& Hoffman, B., B. (1993). Mechanism of bradykinin-induced venodilation in human. Journal of Cardiovascular Pharmacology, 21, 241-8.

Daly, R. N., Roberts, M. I., Ruffolo, R. R., \& Hieble, J. P. (1988). The role of neuropeptide $\mathrm{Y}$ in vascular sympathetic neurotransmission may be enhanced in hypertension. Hypertension, 6, S535-8.

Davis, M. J., Donovitz, J. A., \& Hood, J. D. (1992). Stretch-activated singlechannel and whole cells currents in vascular smooth muscle cells. American Journal of Physiology, 262, C1083-88.

DeSouza, C., Shapiro, L.F., Clevenger, C.M., Dinenno, F.A., Monahan, K.D., Tanaka, H. \& Seals, D.R. (2000). Regular aerobic exercise prevents and restores agerelated declines in endothelium-dependent vasodilation in healthy men. Circulation, 102, 1351-64.

Eldor, A., Hoover, E. L., Pett, Jr., S. B., Gay, Jr., W. A., Alonso, D. R. \& Weksler, B. B. (1991). Prostacyclin production by arterialized autogenous venous grafts in dogs. Prostaglandins, 22, 485-499. 
Escobales, N., Longo, E., Cragoe, E. J., Danthuluri, N. R., \& Brock, T. (1990). Osmotic activation of $\mathrm{Na}^{2+}-\mathrm{H}^{+}$exchange in human endothelial cells. American Journal of Physiology, 259, C640-6.

Faber, J. E., Gettes, D. R., \& Gianturco, D. P. (1988). Microvascular effects of atrial natriuretic peptide factor. Interaction with alpha-1 and alpha-2 adrenoreceptors. Circulation Research, 63, 415-28.

Falcone, J. C., \& Bohlen, H. G. (1990). EDRF from rat intestine and skeletal muscle venules causes dilation of arterioles. American Journal of Physiology, 258, H515-23.

Fehling, P. C., Arciero, P. J., MacPherson, C. J. \& Smith, D. L. (1999). Reproducibility of resting peripheral blood flow using strain gauge plethysmography. International Journal of Sports Medicine, 20, 555-559.

Figueroa, R., Omar, H. A., Tejani, N., \& Wolin, M. S. (1993). Gestational diabetes alters human placental vascular responses to changes in oxygen tension. American Journal of Obstetrics and Gynecology, 168, 1616-22.

Flavahan, N. A. (1991). The role of vascular alpha2-adrenoreceptors as cutaneous thermosensors. News in Physiological Science, 6, 251-55.

Fried, G. \& Samuelson, U. (1991). Endothelin and neuropeptide Y are vasoconstrictors in human uterine blood vessels. American Journal of Obstetrics and Gynecology, 164, 1330-36.

Fung, Y. C., \& Liu, S. Q. (1992). Strain distribution in small blood vessels with zero-stress state taken in consideration. American Journal of Physiology, 262, H544-52.

Gascho, J. A., Fanelli, C., \& Zelis, R. (1989). Aging reduces venous distensibility and the venodilatory response to nitroglycerin in normal subjects. American Journal of Cardiology, 63, 1267-70.

Gerhard, M., Roddy, M., Creager, S.J. \& Creager, M.A. (1995). Aging progressively impairs endothelium-dependent vasodilation in forearm resistance vessels of humans. Hypertension, 27, 849-53.

Gizdulich, P. and Michelutti, M. (1983). Strain gauge venous occlusion plethysmography: Evidence of a trend in repeated blood flow measurements. Methods in Informative Medicine, 3, 204-209.

Glick, M.R., Gehman, J.D., and Gascho, J. A. (1993). Endothelium-derived nitric oxide reduces baseline venous tone in awake instrumented rats. American Journal of Physiology, 265, H47-51. 
Gothert, M., Molderings, G. J., Fink, M., \& Schlicker, E. (1991). Heterogeneity of presynaptic serotonin receptors on sympathetic neurons in blood vessels. Blood Vessels, 28, 11-18.

Greenberg, S. S., Diecke, F. P. J., Peevy, K., \& Tanaka, T. P. (1990). Release of norepinephrine from adrenergic nerve endings of blood vessels is modulated by endothelium-derived relaxing factor. American Journal of Hypertension, 3, 211-18.

Hakim, T. S., Grunstein, M. M., \& Michael, R. P. (1992). Opiate action in the pulmonary circulation. Pulmonary Pharmacology, 5, 159-65.

Hardebo, J. E., Kahrstrom, J., Owman, C., \& Salford, L. G. (1987). Vasomotor effects of neurotransmitters and modulators on isolated human pial veins. Journal of Cerebral Blood Flow and Metabolism, 7, 612-18.

Haegerstrand, A., Dalsgaard, C. J., Jonzon, B., Larsson, O. \& Nilsson, J. (1990). Calcitonin gene-related peptide stimulates proliferation of human endothelial cells. Proceedings in National Academy of Sciences, 87, 3299-03.

Hellstrand, P., Jorup, C., \& Lydrup, M. L. (1984). O $\mathrm{O}_{2}$ consumption, aerobic glycolysis and tissue phosphagen content during activation of the $\mathrm{Na}+/ \mathrm{K}+$ pump in rat portal vein. European Journal of Physiology, 401, 119-24.

Henrion, D., Klaagen, A., \& Bevan, J. A. (1992). Extracellular sodium modulates flow and stretch-induced constriction in opposite directions (Abstract). FASEB J, 6, A1545.

Hermsmeyer, K. (1991). Differences in calcium channels in vascular muscle hypertension. American Journal of Hypertension, 4, 412S-15S.

Hill, S. J. (1991). Histamine receptors and interactions between second messenger transduction systems. Agents and Actions, 33, 145-59.

Hokanson, E., Sumner, D. S. \& Strandness, D. E. Jr. (1999). An electrically calibrated plethysmograph for direct measurement of limb flow. IEEE Transactions on Biomedical Engineering, 22, 25-29.

Honig, C. R., Gayeski, T. E., Clark, A., \& Clark, P. A. (1991). Arteriovenous oxygen diffusion shunt is negligible in resting and working gracilis muscles. American Journal of Physiology, 261, H2031-43.

House, S. D. \& Johnson, P. C. (1986). Miscrovascular pressure in venules of skeletal muscle during arterial pressure reduction. American Journal of Physiology, 250, H828-37. 
Ibrahim, S., MacPherson, D. R., and Goldhaber, S. Z. (1995). Chronic venous insufficiency: mechanisms And management. American Heart Journal, 7, 856-860.

Ikenouchi, H., Iizuka, M., Sato, H., Momomura, S., Serizawa, T. \& Sugimoto, T. (1990). Forearm venous distensibility in relation to severity of symptoms and hemodynamic Data in patients with congestive heart failure. Japanese Heart Journal, 17,34-39.

Johnson, P. C. (1986). Autoregulation of blood flow. A brief review. Circulation Research, 59, 483-495.

Kent, K. C., Collins, C. J., Schwerin, F. T., Raydouwel-Hury, M. K., \& Ware, J. A. (1993). Identification of functional $\mathrm{PGH}_{2} / \mathrm{TxA}_{2}$ receptors on human endothelial cells. Circulation Research, 72, 958-65.

Kobari, M., Gototh, F., \& Fukuuchi, Y. (1985). Effects of (D-Met2, Pro5)enkephalinamide and naloxone on pial vessels in cats. Blood Flow Metabolism, 5, 349 .

Kobayashi, S., Gong, M. C., Somilyo, A. V., \& Somilyo, A. P. (1991). Ca2+ channel blockers distinguished between $\mathrm{G}$ protein-coupled pharmacomechanical $\mathrm{Ca} 2+$ release and Ca2+ sensitization. American Journal of Physiology, 260, C364 70 .

LeJemtel, T. H., Katz, S., Jondeau, C., \& Solomon, S. (1992). Critical analysis of methods for assessing regional blood flow and their reliability in clinical medicine. Chest, 8, 219S-222S.

Leppaluoto, J., \& Ruskoaho, H. (1992). Endothelin peptides: biological activities, cellular signaling and clinical significance. Annals in Medicine, 24, 153-61.

Li, Q., Feenstra, M., Pfaffendorf, M., Eijsman, L. \& van Zwieten, P. A. (1996). Comparative vasoconstrictor effects of angiotensin II, III, and IV in human isolated saphenous vein. Journal of Cardiovascular Physiology, 29, 451-6.

Lowell, R. C., Glovickzi, P. \& Miller, V. M. (1992). In vitro evaluation of endothelial and smoothe muscle function of primary varicose veins. Journal of Vascular Surgery, 16, 679-86.

Luu, T. N., Chester, A. H., O’Neil, G. S., Tadjkarimi, S., \& Yacoub, M. H. (1992). Effects of vasoactive neuropeptides on human saphenous vein. British Heart Journal, 67, 474-77. 
Luu, T. N., Dashwood, M. R., Chester, A. H., Tadjkarimi, S., \& Yacoub, M. H. (1993). Action of vasoactive intestinal peptide and distribution of its binding sites in vessels used for coronary artery bypass grafts. American Journal of Cardiology, 71 , 1278-82.

Malmqvist, U., Arner, A., \& Uvelius, B. (1991). Lactate dehydrogenase activity and isoform distribution in normal and hypertrophic smoothe muscle tissue from the rat. Pfluegers Archives, 419, 230-34.

Marieb, E. M. (1992). Human Anatomy And Physiology, 2nd ed., (pp. 638639). Redwood City, CA. The Benjamin\Cummings Publishing Co.

Martin, D. S., \& McNeil, J. R. (1991). Whole body vascular capacitance response to vasopressin is mediated by autonomic function. American Journal of Physiology, 261, H493-9.

Masaki, T., Kimura, S., Yanagisawa, M., \& Goto, K. (1991). Molecular and cellular mechanism of endothelin regulation. Circulation, 84, 1457-68.

Mathie, R. T., Alexander, B., Ralevic, V., \& Burnstock, G. (1991). Adenosinemediated dilatation of the rabbit hepatic arterial bed is mediated by alpha 2 purinoreceptors. British Journal of Pharmacology, 103, 1103-7.

McKardle, W. D., Katch, F. I., and Katch, V. L. (1996). Exercise Physiology,

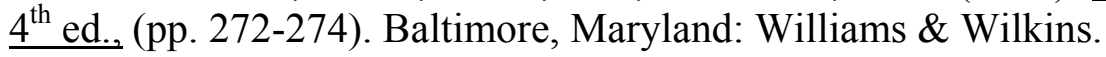

Mellander, S., Anderson, P. O., Afzelius, L. E., \& Hellerstrand, P. (1982). Neural beta-adrenergic dilatation of the facial vein in man. Acta Physiologica Scandinavia, 114, 393-99.

Mizuno, K., Nimura, S., Tani, S. M., Haga, H., Inagami, T., \& Fukuchii, S. (1991). Direct proof for local generation and release of angiotensin II in peripheral human vascular tissue. American Journal of Physiology, 4, 67S-72S.

Moncada, S., Palmer, R. M. J., \& Higgs, E. A. (1991). Nitric oxide. Physiology, pathophysiology, and pharmacology. Pharmacological Reviews, 43, 10942.

Monos, E., Berczi, V., and Nadasy, G. (1995). Local control of veins: biomechanical, metabolic, and humoral aspects. Physiological Reviews, 75, 611-665.

Mortensen, J. D., Talbot, S. \& Burkart, J. A. (1990). Cross-sectional internal diameters of human cervical and femoral blood vessels. Relationship to subject's sex, age, and body size. Anatomy Research, 226, 115-24. 
Nantel, F., Rouissi, N., Rhaleb, N. E., Dion, S., Drapeau, G., \& Regoli, D. (1990). The rabbit jugular vein is a contractile NK-1 receptor system. European Journal of Pharmacology, 179, 457-62.

Naruse, K., \& Sokabe, M. (1993). Involvement of stretch-activated ion channels in $\mathrm{Ca}^{2+}$ mobilization to mechanical stretch in endothelial cells. American Journal of Physiology, 264, C1037-44.

Neubauer, J., Bieniaszewski, L., Kruszewski, P., Swierblewski, E., Juzwa, W., Krupa-Wojciechowska, B. (2000). Assessment of plethysmographic indices repeatability according to body position, choice of forearm and method of measurements. American Journal of Physiology, 3, 575-582.

Onohara, T., Okadome, K., Yamamura, S., Komori, K., Ishii, T., Odashiro, T., \& Sugimachi, K. (1993). Impaired endothelial prostacyclin production of the canine vein graft in a poor distal runoff limb. Surgery, 113, 700-8.

Pallares, L. C. M., Deane, C. R., Baudouin, S. V., and Evans, T. W. (1994). Strain gauge plethysmography and doppler ultrasound in the measurement of limb blood flow. European Journal of Clinical Investigation, 24, 279-286.

Pan, HYM, Hoffman, B.B., Pershe, R.A. \& Blaschke, T. F. (1986). Decline in beta adrenergic receptor-mediated vascular relaxation with aging in man. Journal of Pharmacology and Experimental Therapeutics, 239, 802-807.

Papageorgiou, P., \& Morgan, K. G. (1990). The nuclear-cytoplasmic $\mathrm{Ca}^{2+}$ gradient in single mammalian vascular smoothe muscle cells. Proceedings in Sociology and Experimental Biological Medicine, 193, 331-34.

Queroy, A., \& Verdetti, J. (1992). Cooperative gating of chloride channel subunits in endothelial cells. Biochemistry and Biophysiologica Acta, 1108, 159-68.

Raya, T. E., Gay, R. G., \& Goldman, S. (1990). Selective vasopressin inhibition in rats with heart failure decreases afterload and results in venodilation. Journal of Pharmacology Experimental Therapeutics, 255, 1015-1020.

Regoli, D., Dion, S., Rhaleb, N. E., Rouissi, N., Tousignant, C., \& Jukic, D. (1989). Selective agonists for receptors of substance $\mathrm{P}$ and related neurokinins. Biopolymers, 28, 81-90.

Rice, T. L. (1989). Treatment of esophageal varices. Clinical Pharmacology, 8 , 122-31.

Rizzi, A., Quaglio, D., Vasquez, G., Mascoli, F., Amadesi, S., Calo, G., Regoli, D., and Zamboni, P. (1998). Effects of vasoactive agents in healthy and diseased human saphenous veins. Journal of Vascular Surgery, 7, 855-861. 
Romano, S., \& Gizdulich, P. (1980). Reproducibility of strain gauge venous occlusion plethysmography in long run measurements in man. Methods and Findings in Experimental Clinical Pharmacology, 35, 83-87.

Rongen, G. A., Smits, P. \& Thien, T. (1992). Endothelium and the regulation of vascular tone with emphasis on the role of nitric oxide. Physiology, pathophysiology and clinical implications. Netherlands Journal of Medicine, 44, 2635.

Rubanyi, G. M. \& Vanhoutte, P. M. (1988). Heterogeneity of endotheliumdependent responses to acetylcholine in canine femoral arteries and veins. Blood Vessels, 25, 75-81.

Sansivero, G. E. (1998). Venous anatomy and physiology. Journal of Intravenous Nursing, 6, S107-14.

Sato, H., Ikenouchi, H., Aoyagi, T., Matsui, H., Mochizuki, T., Momomura, S., Serizawa, T., Iizuki, M. \& Sugimoto, T. (1989). Pathophysiology and evaluation of congestive heart failure on the basis of venous characteristics. Japanese Circulation Journal, 23, 141-145.

Schina, M. J., Neumyer, M. M., Healy, D. A., Atnip, R. G., \& Thiele, B. L. (1993). Influence of age on venous physiologic parameters. Journal of Vascular Surgery, $7,749-752$.

Simon, G. (1978). Venous changes in renal hypertensive rats: role of humoral factors. Blood Vessels, 15, 311-21.

Simon, G. (1990). Increased vascular wall sodium in hypertension. Where did it come from? How did it get there, and what does it do there? Clinical Science, 78, 533-40.

Sinoway, L. I., Musch, T. I., Minotti, J. R., and Zelis, R. (1986). Enhanced maximal metabolic vasodilation in the dominant forearms of tennis players. Journal of Applied Physiology, 61, 673-678.

Sjoberg, T., Andersson, K. E., Norgren, L., \& Steen, S. (1987). Comparative effects of some calcium-channel blockers on human peripheral arteries and veins. Acta Physiologica Scandinavia, 130, 419-27.

Soloviev, A. I., \& Basilyuk, O. V. (1993). Evidence for decrease in myofilament responsiveness to $\mathrm{Ca}^{2+}$ during hypoxia in spontaneously active vascular smoothe muscle in rats. Experimental Physiology, 78, 395-402. 
Sudhir, K., Angus, J. A., Esler, M. D., Jennings, G. L., Lambert, G. W., \& Korner, P. I. (1990). Altered venous responses to vasoconstrictor agonists and nerve stimulation in human primary hypertension. Clinical Experiments in Hypertension, $\underline{12,1119-28 .}$

Sung, C. P., Arleth, A. J., \& Feuerstein, G. Z. (1991). Neuropeptide Y upregulates the adhesiveness of human endothelial cells for leukocytes. Circulation Research, 68, 314-18.

Sumner, A., Zelis, R., Bennet, M., Gascho, J. A. (1989). Effect of sympatheticinduced venoconstriction in normal subjects. American Journal of Cardiology, 63, 973-976.

Supiano, M. A., Hogikyan, R. V., Stoltz, A. M., Orstan, N., \& Halter, J. B. (1991). Regulation of venous alpha-adrenergic responses in older humans. American Journal of Physiology, Endocrinology and Metabolism, 260, E599-E607.

Szabo, C., Berczi, V., Schneider, F., Kovach, A. G. B. \& Monos, E. (1992). Role of endothelium in the response of the vein wall to magnesium withdrawal. Pfluegers Archives, 420, 140-5.

Takata, S., Fukase, M., Takagi, Y., Tokunaga, O., \& Fujita, T. (1990). Rapid $\mathrm{Ca}^{2+}$ refilling system of intracellular stores in human vascular endothelial cells. Biochemistry and Biophysiology in Research Community, 167, 933-40.

Thulesius, O., Ugaily-Thulesius, L., Gjores, J. E. \& Neglen, P. (1988). The varicose saphenous vein, functional and ultrastructural studies, with special reference to smooth muscle. Phlebology, 3, 89-95.

Tsujimoto, G., Lee, CH. \& Hoffman, B. B. (1986). Age-related decrease in beta adrenergic-mediated vascular smoothe muscle relaxation. Journal of Pharmacology and Experimental Therapeutics, 239, 411-415.

Tsukahara, H., Gordienko, D. V., \& Goligorsky, M. S. (1993). Continuous monitoring of nitric oxide release from human umbilical vein endothelial cells. Biochemistry and Biophysiology Research Community, 193, 722-29.

Tsuru, H., Kohno, S., Iwata, M., \& Shigel, T. (1987). Characterization of histamine receptors in isolated rabbit veins. Journal of Pharmacology and Experimental Therapeutics, 243, 696-702.

Wali, F. A., Greenridge, E., \& Tugwell, A. C. (1988). Effect of varapamil on the contraction produced by high potassium and by noradrenaline in human isolated saphenous vein. Acta Physiologica Hungary, 72, 115-21. 
Walsh, J. A., Hyman, Ch. \& Maronde, R. F. (1969). Venous distensibility in essential hypertension. Cardiovascular Research, 3, 338-349.

Webb, D. J., Benjamin, N., Cockcroft, J. R., \& Collier, J. G. (1989). Augmentation of sympathetic venoconstriction by angiotensin II in human dorsal hand veins. American Journal of Hypertension, 2, 721-23.

Wecht, J. M., De Meersman, R. E., Weir, P. J., Bauman, A. W. \& Grimm, D. R. (2000). Effects of autonomic disruption and inactivity on venous vascular function. American Journal of Physiology of Heart Circulation Physiology, 278, H515-H520.

Woldhuis, B., Tangelder, G. J., Slaaf, D. W., \& Reneman, R. S. (1992). Concentration profile of blood platelets differs in arterioles and venules. American Journal of Physiology, 262, H1217-23.

Wu, N. W., Jalkanen, S., Streeter, P. R. \& Butcher, E. C. (1988). Evolutionary conservation of tissue-specific lymphocyte-endothelial cell recognition mechanisms involved in lymphocyte homing. Journal of Cellular Biology, 107, 1845-51.

Yanagisawa, M., Kurhara, H., Kimura, S., Tomobe, Y., Kobayashi, M., Mitsui, Y., Yazaki, Y., Goto, K., \& Masaki, T. (1988). A novel potent vasoconstrictor peptide produced by vascular endothelial cells. Nature London, 332, 411-15.

Yang, Z., Von Segesser, L., Bauer, E., Stulz, P., Turina, M., \& Luscher, T. F. (1991). Different activation of the endothelial 1-arginine and cyclooxygenase pathway in the human internal mammary artery and vein. Circulation Research, 68, 52-60.

Zhang, A. Carella, A., Altura, B. T., \& Altura, B. M. (1991). Interactions of magnesium and chloride ions on tone and contractility of vascular smoothe muscle. European Journal of Pharmacology, 203, 223-235. 


\section{Vita}

Jennifer P. Ortego was born on February 13, 1974, in Ville Platte, Louisiana, to Chris and Hedy Pitre. She was raised in Eunice, Louisiana, where she attended East Elementary, Central Middle, Eunice Junior High and Eunice High School. Jennifer then attended Louisiana State University at Eunice, and then transferred to Louisiana State University at Baton Rouge, where she graduated in May of the year 1998 and received the degree of Bachelor of Science in kinesiology, with a concentration in fitness studies. She entered the graduate program at Louisiana State University in 1999, and expects to be awarded the degree of Master of Science in kinesiology in May 2002.

In January of 2002, Jennifer plans to pursue a career in the medical field. Jennifer is currently working as a trainer/instructor at Goudeau's Health Club in Baton Rouge, Louisiana. 